\title{
Coupling ATMD System for Seismic Response Control of Two Adjacent Buildings
}

\author{
Kwan-Soon Park ${ }^{1}$ and Seung-Yong Ok iD $^{2}$ \\ ${ }^{1}$ Professor, Department of Architectural Engineering, Dongguk University-Seoul, Seoul 04620, Republic of Korea \\ ${ }^{2}$ Associate Professor, Department of Civil, Safety and Environmental Engineering, Hankyong National University, \\ Anseong 17579, Republic of Korea \\ Correspondence should be addressed to Seung-Yong Ok; syok@hknu.ac.kr
}

Received 27 September 2018; Revised 19 February 2019; Accepted 27 March 2019; Published 22 April 2019

Academic Editor: Pedro A. Costa

Copyright (c) 2019 Kwan-Soon Park and Seung-Yong Ok. This is an open access article distributed under the Creative Commons Attribution License, which permits unrestricted use, distribution, and reproduction in any medium, provided the original work is properly cited.

\begin{abstract}
This study deals with optimal control of the coupling active tuned mass damper (ATMD) system for two neighboring structures under earthquake excitations. It also investigates the seismic performances of the proposed system including the issues on actuator failure problems. The conventional control approach is to use two ATMDs independently where each ATMD is individually installed at each structure without any connection between two structures. Since this uncoupling configuration does not allow transferring its control force to the other structure, it cannot adapt to emergency situation in which one of the two actuators becomes inoperable due to the power cuts or outages. On the other hand, the proposed control approach is to use a coupling ATMD system where two ATMDs with one mass being shared are installed to interconnect two structures. Hence, the proposed coupling ATMD system can transmit the control force of the remaining actuator to another structure through the interconnection configuration so that it can adapt to the one-side actuator failure. In a numerical example, the conventional independent and newly proposed coupling systems have been optimally designed to have similar control performance in normal operational conditions, and their performances have been compared to each other under the malfunction conditions of one-side actuator. Their comparative results verified the outstanding adaptive performance of the proposed coupling ATMD system over the independent ATMD system. The independent ATMD system showed considerably degraded control performance compared to its own normal control performance, whereas the proposed system exhibits much improved control performance over the independent ATMD system by fully utilizing the other normally operating actuators through the coupling configuration.
\end{abstract}

\section{Introduction}

The seismic response control problem of two neighboring buildings has been successfully addressed by introducing a method of interconnecting two adjacent buildings with control devices such as linear passive [1-3], nonlinear passive [4-6], active [7-9], semiactive [10-12], and hybrid [13, 14] systems. This is due to the fact that there exists optimal control capacity in reducing the responses of the neighboring parallel structures interconnected with the control device $[1,4]$. In other words, the responses of both buildings can be considerably reduced in the vicinity of the optimal point, whereas too much or too little control capacity far from the optimal point may adversely increase the structural responses. In this regard, the interbuilding connection approach is advantageous in that it can achieve the control performance as high as possible while saving the control capacity. We have also investigated the applicability of the interbuilding approach for the adjacent buildings by using various approaches. In [8], we proposed a preference-based design approach to balance several design objectives such as interstory drift, instantaneous control force, instantaneous control power, and total control energy when these design objectives are mutually conflicting. In [9], we proposed a reference-model-tracking fuzzy control technique where the reference model is an ideal desirable model constructed by assigning the target damping ratios to the first few dominant modes in modal space, and the fuzzy control is able to make the structural behavior track the desirable behavior of 
the reference model. In [13], we dealt with the hybrid control system consisting of passive damper and tendon-type active device where the active devices are installed inside the buildings and the passive dampers are used as the link members. In [14], we dealt with the vibration control problem of two new and old neighboring buildings which is formulated as a constrained optimization problem since the old building has the limitations on installation of additional control devices. Recently, Ok and Kim [3] proposed a new vibration control approach to solve the challenging problem that the existing interbuilding connection approach is ineffective in case of twin structures due to the symmetry of the behaviors of the twin structures. Although various types of control systems have been proposed for the interbuilding connection configuration, application of active tuned mass damper (ATMD) to two adjacent buildings has not been studied yet.

In the application of the control system, one of the main concerns is to maintain the system as fail-safe. Here, the system being "fail-safe" means that the control system prevents or mitigates unsafe consequences caused by failure due to the natural hazards or malfunction due to the human error. Most controllers show good performance in normal operational condition, but they are not guaranteed to perform satisfactorily under abnormal condition or unexpected emergency. Specifically, the actuator in the active control system could malfunction due to the power cuts or outages during the earthquake. Therefore, the earthquake-resistant control system needs to have the adaptive performance against the actuator failure. To date, this issue on the fault tolerant system has not been addressed for the earthquakeexcited adjacent buildings.

As one feasible way to overcome this limitation of the active control system, it can be considered to make the system a hybrid system combining active and passive systems. In case of failure in the active system, the passive system is still valid so that the control system can prevent the system from being unsafe or at least mitigate significant performance degradation. In this regard, we employ the ATMD system consisting of the passive TMD and the active actuator as the hybrid system which has been successfully applied to the vibration control problem of the single building by several researchers [15-18].

A typical way is to install two ATMDs in two separate buildings, that is, one ATMD in a building. Since this independent control approach has no connection between two buildings, no control force interacts between the two buildings, and the two buildings exhibit individual behavior. However, if the two buildings are interconnected, the control force of an ATMD installed in one building can be transferred to another building, and vice versa. This implies that when the active actuator of one building is destroyed and only the passive TMD mode is operated, the active control force of a normally operating actuator in the other building can be transmitted to the actuator-destroyed building, thereby contributing the normally operating active force to the passive control performance further. For this reason, in order to facilitate the seismic performance of the ATMD system in a better way, we employ the interbuilding coupling configuration as an application of the ATMD system to the adjacent buildings. The coupling ATMD system is a system in which the ATMD system is placed between two buildings to connect two buildings interactively.

Another advantage of this approach is that it has more space in the installation and thus there is much more room for the stroke of the mass block than the conventional system. The TMD type of control system sacrifices an excessive stroke of the mass block instead of reducing the vibration of the structure. Hence, when the ATMD is installed inside a building, its design is subjected to space constraint of the building. The ATMD system should be designed not to exceed its maximum stroke allowed in the installation space. On the other hand, the proposed coupling ATMD system can fully utilize the space between two buildings, so the constraint on the stroke is relatively less strict than the independent ATMD system.

The main purpose of this study is to propose a new coupling-type ATMD system for the seismic response control of the adjacent buildings and demonstrate its emergency performance against the one-side failure of the two actuators. For the implementation of this purpose, we first introduce the equations of motion of the independent and coupling ATMD systems and the active control algorithm, and the optimal design technique for both systems is described next. Then, an illustrative example is presented to demonstrate the performances of the proposed coupling approach through comparison with the independent control approach, finally being followed by conclusion.

\section{Problem Statement}

2.1. System Representation. Let us consider two configurations of the ATMD system for the adjacent structures subjected to earthquake excitations. One is the independent ATMD system where the two ATMDs are independently installed at each building and no connection exists between two buildings, as shown in Figure 1(a). The other is the coupling ATMD system where two ATMDs with the mass being shared are installed to couple the two buildings, as shown in Figure 1(b). Thus, the two structures and the coupling ATMD are all connected to each other. For simplicity, the two systems are referred to as IAS (independent ATMD system) and CAS (coupling ATMD system), respectively.

First, let us consider the IAS representation. Since it is widely known that the top floor is the most efficient for the application of the ATMD to a single building, we consider that the independent ATMD is installed on top of a building. When the building is subjected to earthquake excitations, the equations of motion can be expressed separately by two state space equations as follows:

$$
\begin{aligned}
\dot{\mathbf{z}}_{1}= & \mathbf{A}_{\mathbf{s}_{1}} \mathbf{z}_{1}+\mathbf{B}_{\mathbf{w}_{1}} \ddot{x}_{\mathrm{g}}+\mathbf{B}_{\mathbf{u}_{1}} \mathbf{u}_{1} \\
& \Longleftrightarrow\left\{\begin{array}{c}
\dot{\mathbf{x}}_{1} \\
\ddot{\mathbf{x}}_{1}
\end{array}\right\}=\left[\begin{array}{c}
\mathbf{I} \\
-\mathbf{M}_{\mathrm{IAS}_{1}}^{-1} \mathbf{K}_{\mathrm{IAS}_{1}}-\mathbf{M}_{\mathrm{IAS}_{1}}^{-1} \mathbf{C}_{\mathrm{IAS}_{1}}
\end{array}\right]\left\{\begin{array}{c}
\mathbf{x}_{1} \\
\dot{\mathbf{x}}_{1}
\end{array}\right\} \\
& +\left[\begin{array}{c}
\mathbf{0} \\
-\mathbf{1}
\end{array}\right] \ddot{x}_{\mathrm{g}}+\left[\begin{array}{c}
\mathbf{0} \\
\mathbf{M}_{\mathrm{IAS}}^{-1} \mathbf{b}_{\mathbf{u}_{1}}
\end{array}\right] u_{T}^{1},
\end{aligned}
$$




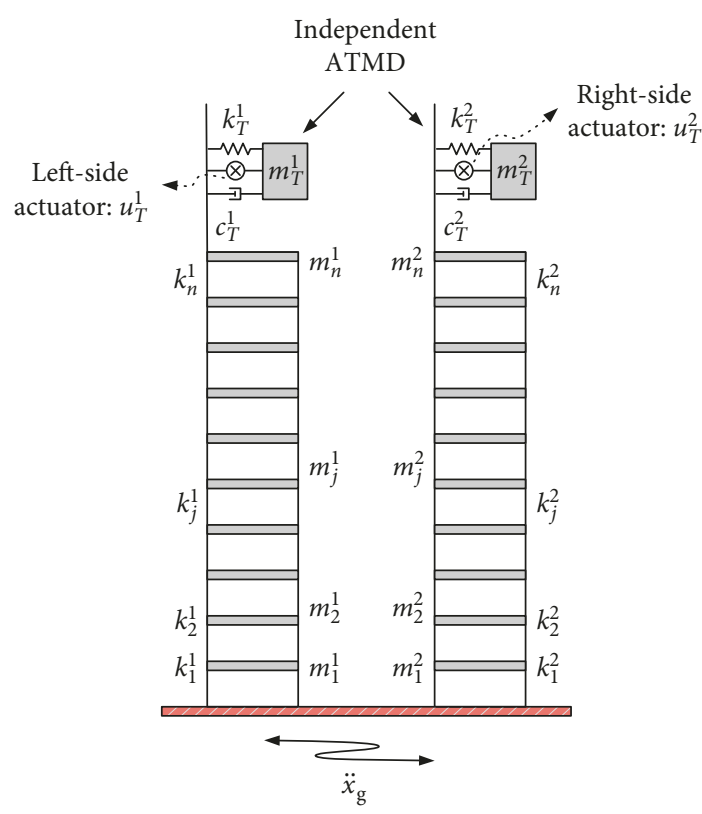

(a)

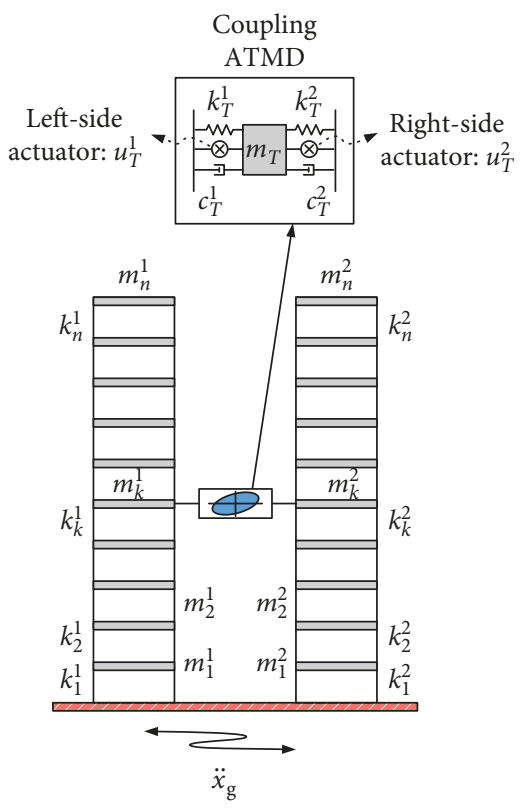

(b)

FIgURE 1: Configurations of independent ATMD and coupling ATMD systems for seismic reinforcement of adjacent buildings. (a) Independent ATMD system. (b) Coupling ATMD system.

$$
\begin{aligned}
\dot{\mathbf{z}}_{2}= & \mathbf{A}_{\mathbf{s}_{2}} \mathbf{z}_{2}+\mathbf{B}_{\mathbf{w}_{2}} \ddot{x}_{\mathrm{g}}+\mathbf{B}_{\mathbf{u}_{2}} \mathbf{u}_{2} \\
& \Longleftrightarrow\left\{\begin{array}{c}
\dot{\mathbf{x}}_{2} \\
\ddot{\mathbf{x}}_{2}
\end{array}\right\}=\left[\begin{array}{c}
\mathbf{0} \\
\mathbf{I} \\
-\mathbf{M}_{\mathrm{IAS}_{2}}^{-1} \mathbf{K}_{\mathrm{IAS}_{2}}-\mathbf{M}_{\mathrm{IAS}_{2}}^{-1} \mathbf{C}_{\mathrm{IAS}_{2}}
\end{array}\right]\left\{\begin{array}{c}
\mathbf{x}_{2} \\
\dot{\mathbf{x}}_{2}
\end{array}\right\} \\
& +\left[\begin{array}{c}
\mathbf{0} \\
-\mathbf{1}
\end{array}\right] \ddot{x}_{\mathrm{g}}+\left[\begin{array}{c}
\mathbf{0} \\
\mathbf{M}_{\mathrm{IAS}_{2}}^{-1} \mathbf{b}_{\mathbf{u}_{2}}
\end{array}\right] u_{T}^{2},
\end{aligned}
$$

where the subscript $i=1,2$ denotes the two buildings respectively, e.g., 1 for left building and 2 for right building; $\mathbf{z}_{i}$ is the state vector consisting of displacements $\mathbf{x}_{i}$ and velocities $\dot{\mathbf{x}}_{i}$ of the $i$-th building with $i$-th independent ATMD; $\mathbf{B}_{\mathbf{w}_{i}}$ is a location vector of positioning a ground acceleration $\ddot{x}_{\mathrm{g}}$ into the corresponding DOF of the $i$-th structure; $\mathbf{1}$ is a column vector of $1 \mathrm{~s} ; \mathbf{B}_{\mathbf{u}_{i}}$, and $\mathbf{u}_{i}$ correspond to the location and force vectors of the control forces $u_{T}^{1}$ and $u_{T}^{2}$ exerted by the two actuators of ATMDs. The control forces $u_{T}^{1}$ and $u_{T}^{2}$ will be determined by the control algorithm which will be described later in more details; and $\mathbf{b}_{\mathbf{u}_{i}}$ is a column vector whose element is +1 for the DOF of the $i$-th TMD mass, -1 for the top floor of the building, and other elements are 0 if the floor has no actuator; and $\mathbf{M}_{\mathrm{IAS}}, \mathbf{C}_{\mathrm{IAS}}$, and $\mathbf{K}_{\mathrm{IAS}}$ represent the mass, damping coefficient, and stiffness matrices of the $i$-th building with the $i$-th ATMD, respectively. The corresponding mass, damping, and stiffness matrices are defined as

$$
\mathbf{M}_{\mathrm{IAS}_{i}}=\left[\begin{array}{cc}
\mathbf{M}_{i} & \mathbf{0} \\
\mathbf{0} & m_{T}^{i}
\end{array}\right]=\left[\begin{array}{ccccc}
m_{1}^{i} & 0 & \cdots & 0 & 0 \\
0 & m_{2}^{i} & \cdots & 0 & 0 \\
\vdots & \vdots & \ddots & \vdots & \vdots \\
0 & 0 & \cdots & m_{n}^{i} & 0 \\
0 & 0 & \cdots & 0 & m_{T}^{i}
\end{array}\right],
$$

$$
\begin{aligned}
\mathbf{K}_{\mathrm{IAS}_{i}} & =\left[\begin{array}{cc}
\mathbf{K}_{i}+\mathbf{k}_{11}^{i} & \mathbf{k}_{12}^{i} \\
\mathbf{k}_{21}^{i} & k_{T}^{i}
\end{array}\right] \\
& =\left[\begin{array}{ccccc}
k_{1}^{i}+k_{2}^{i} & -k_{2}^{i} & \cdots & 0 & 0 \\
-k_{2}^{i} & k_{2}^{i}+k_{3}^{i} & \cdots & 0 & 0 \\
\vdots & \vdots & \ddots & \vdots & \vdots \\
0 & 0 & \cdots & k_{n}^{i}+k_{T}^{i} & -k_{T}^{i} \\
0 & 0 & \cdots & -k_{T}^{i} & k_{T}^{i}
\end{array}\right], \\
\mathbf{C}_{\mathrm{IAS}_{i}} & {\left[\begin{array}{cccccc}
\mathbf{C}_{i}+\mathbf{c}_{11}^{i} & \mathbf{c}_{12}^{i} \\
\mathbf{c}_{21}^{i} & c_{T}^{i}
\end{array}\right]=\left[\begin{array}{ccccc}
c_{11}^{i} & c_{12}^{i} & \cdots & c_{1 n}^{i} & 0 \\
c_{21}^{i} & c_{22}^{i} & \cdots & c_{2 n}^{i} & 0 \\
\vdots & \vdots & \ddots & \vdots & \vdots \\
c_{n 1}^{i} & c_{n 2}^{i} & \cdots & c_{n}^{i}+c_{T}^{i} & -c_{T}^{i} \\
0 & 0 & \cdots & -c_{T}^{i} & c_{T}^{i}
\end{array}\right], }
\end{aligned}
$$

where $\mathbf{M}_{i}$ and $\mathbf{K}_{i}$ are the mass and stiffness matrices of the $i$-th building whose elements $m_{j}^{i}$ and $k_{j}^{i} \quad(i=1,2$ and $j=$ $1,2, \ldots, n)$ are the mass and stiffness of the $j$-th floor and column of the $i$-th building; $m_{T}^{i}, c_{T}^{i}$, and $k_{T}^{i}$ are the mass, damping coefficient, and stiffness of the $i$-th ATMD, respectively. Thus, these values will be considered as the design variables and determined in the optimization process; the damping matrix of the $i$-th structure $\mathrm{C}_{i}=\left[c_{j k}^{i}\right],(j=$ $1,2, \ldots, n$ and $k=1,2, \ldots, n)$ is assumed to follow a Rayleigh damping modeling, and thus it can be defined to be proportional to mass and stiffness matrices given by $\mathbf{C}_{i}=\alpha \mathbf{M}_{i}+\beta \mathbf{K}_{i}$, where the coefficients $\alpha$ and $\beta$ will be given later in numerical example; $\mathbf{k}_{11}^{i}$ and $\mathbf{c}_{11}^{i}$ are $n \times n$-dimensional matrix with all zeros except for $n$-th $\times n$-th component of $k_{T}^{i}$ 
and $c_{T}^{i}$, respectively; $\mathbf{k}_{12}^{i}$ and $\mathbf{c}_{12}^{i}$ are $n \times 1$ column vectors with all zeros except for $n$-th component of $-k_{T}^{i}$ and $-c_{T}^{i}$, respectively; and $\mathbf{k}_{21}^{i}$ and $\mathbf{c}_{21}^{i}$ are $1 \times n$ row vectors with all zeros except for $n$-th component of $-k_{T}^{i}$ and $-c_{T}^{i}$, respectively.

Next, let us consider the CAS representation. Since the ATMD-coupled buildings show different mode shapes from the previous IAS-controlled buildings, the optimal location of the coupling ATMD is not known a priori. Hence, we assume that the coupling ATMD is installed to interconnect the arbitrary $k$-th floors of the two buildings, as shown in Figure 1(b). Then, the equations of motion can be expressed by the following state space equation such that

$$
\begin{aligned}
& \dot{\mathbf{z}}=\mathbf{A}_{\mathrm{s}} \mathbf{z}+\mathbf{B}_{\mathbf{w}} \ddot{x}_{\mathrm{g}}+\mathbf{B}_{\mathbf{u}} \mathbf{u} \\
& \Longleftrightarrow\left\{\begin{array}{c}
\dot{\mathbf{x}} \\
\ddot{\mathbf{x}}
\end{array}\right\}=\left[\begin{array}{cc}
\mathbf{0} & \mathbf{I} \\
-\mathbf{M}_{\mathrm{CAS}}^{-1} \mathbf{K}_{\mathrm{CAS}} & -\mathbf{M}_{\mathrm{CAS}}^{-1} \mathbf{C}_{\mathrm{CAS}}
\end{array}\right]\left\{\begin{array}{c}
\mathbf{x} \\
\dot{\mathbf{x}}
\end{array}\right\} \\
& +\left[\begin{array}{c}
\mathbf{0} \\
-\mathbf{1}
\end{array}\right] \ddot{x}_{\mathrm{g}}+\left[\begin{array}{c}
\mathbf{0} \\
\mathbf{M}_{\mathrm{CAS}}^{-1} \mathbf{b}_{\mathbf{u}}
\end{array}\right]\left\{\begin{array}{l}
u_{T}^{1} \\
u_{T}^{2}
\end{array}\right\}
\end{aligned}
$$

where $\mathbf{x}$ is the column vector consisting of the displacements of the two buildings with the coupling ATMD; $\mathbf{z}$ is the state vector consisting of displacements $\mathbf{x}$ and velocities $\dot{\mathbf{x}}$ of the two buildings with coupling ATMD; $\mathbf{b}_{\mathbf{u}}$ is an $n \times 2$-sized matrix, of which the first column corresponds to the control force $u_{T}^{1}$ and the second column corresponds to the control force $u_{T}^{2}$. The element of the first column of $\mathbf{b}_{\mathbf{u}}$ is -1 for the DOF of the ATMD mass, +1 for the floor of the left building where the ATMD is installed, and other elements are 0 if the floor has no actuator. The element of the second column of $\mathbf{b}_{\mathbf{u}}$ is -1 for the DOF of the ATMD mass, +1 for the floor of the right building where the ATMD is installed, and other elements are 0 for the DOFs of the floors with no actuator; since the two buildings are interconnected with the coupling ATMD, the mass, damping coefficient, and stiffness matrices are defined as follows:

$$
\begin{aligned}
& \mathbf{M}_{\mathrm{CAS}}=\left[\begin{array}{ccc}
\mathbf{M}_{1} & \mathbf{0} & \mathbf{0} \\
\mathbf{0} & \mathbf{M}_{2} & \mathbf{0} \\
\mathbf{0} & \mathbf{0} & m_{T}^{c}
\end{array}\right], \\
& \mathbf{K}_{\mathrm{CAS}}=\left[\begin{array}{ccc}
\mathbf{K}_{1}+\mathbf{k}_{11}^{1} & \mathbf{0} & \mathbf{k}_{12}^{1} \\
\mathbf{0} & \mathbf{K}_{2}+\mathbf{k}_{11}^{2} & \mathbf{k}_{12}^{2} \\
\mathbf{k}_{21}^{1} & \mathbf{k}_{21}^{2} & k_{T}^{c}
\end{array}\right], \\
& \mathbf{C}_{\mathrm{CAS}}=\left[\begin{array}{ccc}
\mathbf{C}_{1}+\mathbf{c}_{11}^{1} & \mathbf{0} & \mathbf{c}_{12}^{1} \\
\mathbf{0} & \mathbf{C}_{2}+\mathbf{c}_{11}^{2} & \mathbf{c}_{12}^{2} \\
\mathbf{c}_{21}^{1} & \mathbf{c}_{21}^{2} & c_{T}^{c}
\end{array}\right],
\end{aligned}
$$

where $m_{T}^{c}$ is a shared mass of the coupling ATMD; $k_{T}^{c}=$ $k_{T}^{1}+k_{T}^{2}$ and $c_{T}^{c}=c_{T}^{1}+c_{T}^{2}$ are the sum of the left and right stiffness and damping coefficients of the coupling ATMD; $\mathbf{k}_{11}^{i}$ and $\mathbf{c}_{11}^{i}$ are $n \times n$-dimensional matrix with all zeros except for $k$-th $\times k$-th component of $k_{T}^{i}$ and $c_{T}^{i}$, respectively; $\mathbf{k}_{12}^{i}$ and $\mathbf{c}_{12}^{i}$ are $n \times 1$ column vectors with all zeros except for $k$-th component of $-k_{T}^{i}$ and $-c_{T}^{i}$, respectively; $\mathbf{k}_{21}^{i}$ and $\mathbf{c}_{21}^{i}$ are $1 \times n$ row vectors with all zeros except for $k$-th component of $-k_{T}^{i}$ and $-c_{T}^{i}$, respectively; and other matrices such as $\mathbf{M}_{i}, \mathbf{C}_{i}$, and $\mathbf{K}_{i}$ are the same as matrices in equations $(2 \mathrm{a})-(2 \mathrm{c})$.
Differently from IAS, the equations of motion of the two buildings with CAS are coupled to each other. Therefore, the control force of the left ATMD is transferred to the right building through the connection, and vice versa. This is a key feature of the proposed system to provide adaptive control performance for the one-side actuator failure.

Next, we will discuss the active control algorithm to determine the control force $\mathbf{u}_{i}$ in equations (1a) and (1b) for IAS and $\mathbf{u}$ in equation (3) for CAS.

2.2. Active Control Algorithm. Regardless of the configuration of the ATMD system, the active control forces of both ATMD systems can be operated by the same control algorithm, which will be rational for the performance comparison of the two ATMD configurations. While there exist various active control algorithms, we will employ the most common LQR algorithm [19] for both independent and coupling systems. The two independent ATMD systems are designed separately by using equation (1a) or equation (1b), and the proposed coupling system is designed once by using equation (3). For simplicity, we describe the procedure for the proposed coupling system. As for the independent system, all notations are replaced by adding the subscript $i$, e.g., $\mathbf{z}$ is replaced by $\mathbf{z}_{i}$.

Using the feedback scheme, the LQR control force can be determined by

$$
\mathbf{u}=-\mathbf{G}_{\mathbf{u}} \mathbf{z}=-\left[\mathbf{R}_{\mathbf{u}}^{-1} \mathbf{B}_{\mathbf{u}}^{T} \mathbf{P}\right] \mathbf{z}
$$

where $\mathbf{P}$ is a solution matrix to the following algebraic Riccati equation (ARE):

$$
\mathbf{A}_{\mathbf{s}}^{T} \mathbf{P}+\mathbf{P A}_{\mathbf{s}}-\mathbf{P}\left[\mathbf{B}_{\mathbf{u}} \mathbf{R}_{\mathbf{u}}^{-1} \mathbf{B}_{\mathbf{u}}^{T}\right] \mathbf{P}+\mathbf{Q}_{\mathbf{z}}=\mathbf{0}
$$

where $\mathbf{Q}_{\mathbf{z}}$ and $\mathbf{R}_{\mathbf{u}}$ are the weighting matrices on structural state $\mathbf{z}$ and control force $\mathbf{u}$, respectively. Note that the solution $\mathbf{P}$ is a realization of minimizing the performance index defined by

$$
J=\frac{1}{2} \int_{0}^{\infty}\left[\mathbf{z}(t)^{T} \mathbf{Q}_{\mathbf{z}} \mathbf{z}(t)+\mathbf{u}(t)^{T} \mathbf{R}_{\mathbf{u}} \mathbf{u}(t)\right] d t,
$$

where a designer can put an emphasis on any responses of interest by using a relation $\mathbf{Q}_{\mathbf{z}}=\mathbf{C}_{\mathbf{y}}^{T} \mathbf{C}_{\mathbf{y}}$ which leads to $\mathbf{z}^{T} \mathbf{Q}_{\mathbf{z}} \mathbf{z}=\mathbf{z}^{T} \mathbf{C}_{\mathbf{y}}^{T} \mathbf{C}_{\mathbf{y}} \mathbf{z}=\left\{\mathbf{C}_{\mathbf{y}} \mathbf{z}\right\}^{T} \mathbf{C}_{\mathbf{y}} \mathbf{z}=\mathbf{y}^{T} \mathbf{y}$ in equation (7), and the weighting matrix on control forces $\mathbf{R}_{\mathbf{u}}$ can be selected by using a relation $\mathbf{R}_{\mathbf{u}}=\operatorname{diag}\left[r_{T}^{1}, r_{T}^{2}\right]$ in order to put a relative importance between the control forces of two actuators. In this study, the output vector to be minimized, i.e., $y$ in equation (7) is chosen as the displacements and velocities of the structures except for the TMDs' responses, and thus the output matrix $\mathbf{C}_{\mathbf{y}}$ for both IAS and CAS can be defined as a matrix in which the diagonal elements corresponding to the displacements and velocities of the structures are all 1 s and the remaining elements are all 0 s including the diagonal elements corresponding to the DOFs of displacements and velocities of the TMDs. Given $\mathbf{Q}_{\mathbf{z}}=\mathbf{C}_{\mathbf{y}}^{T} \mathbf{C}_{\mathbf{y}}$, the optimal control gain $\mathbf{G}_{\mathbf{u}}$ is mainly dependent upon the selection of two parameters $r_{T}^{1}$ and $r_{T}^{2}$ in $\mathbf{R}_{\mathbf{u}}$. Thus, these two parameters become the design variables of the two control systems such as IAS and CAS. The control force $\mathbf{u}$ in equation (5) is substituted into equation (3), and finally, the seismic response can be simulated by 


$$
\dot{\mathbf{z}}=\left(\mathbf{A}_{\mathbf{s}}-\mathbf{B}_{\mathbf{u}} \mathbf{G}_{\mathbf{u}}\right) \mathbf{z}+\mathbf{B}_{\mathbf{w}} \ddot{x}_{\mathrm{g}} .
$$

\section{Optimal Design of Independent and Coupling ATMD Systems}

In this section, we will describe the optimal design of the two ATMD-based control systems. The ATMD system is a hybrid control system consisting of passive TMD and active actuator where adding active control capacity to the passive TMD system allows for not only significant improvement of the seismic performance of the structure but also adaptive performance against actuator failure. The independent ATMD system is considered as a reference control system for comparison with the proposed coupling ATMD system. Thus, we will first describe the IAS design procedure and next describe the CAS design procedure based on the genetic algorithm (GA) [20]. GA has been successfully used by the same authors $[8,13,14]$ for the optimal design of the coupling control system of adjacent buildings, and similar studies can be found in the literature [21-23].

3.1. IAS Design. The optimal design of the IAS is composed of two steps: the first step is to select the optimal parameters of the passive TMD system and the second step is to determine the optimal gain matrix for active control of the actuator. Since two ATMD systems for building 1 and for building 2 are independent of each other, we can repeat the design process independently for building 1 and building 2 .

The first step is to determine the mass, damping, and stiffness of the passive TMD. It usually begins with the designer's choice on the mass ratio of the TMD. Generally, the TMD with larger mass ratio can exhibit the better performance than the TMD with smaller mass ratio in many cases [24]. Thus, the mass ratio of the TMD is a main factor directly affecting the control performance. For fair comparison, we will set the same mass ratio to IAS and CAS. Given the TMD mass ratio, various TMD design formulas [25-27] can be applied to obtain the TMD parameters. Although these design formulas have their own advantages and some of them may perform better on our problem, we simply adopt the most widely known Den Hartog design formula [25]. The reason is that the main purpose of this study is to show the adaptive control performance of the proposed CAS over the IAS, not to compete with specific control algorithms.

Given the TMD mass ratio, the mass, damping, and stiffness of the TMD can be determined based on the following formulas:

$$
\begin{aligned}
\mu & =\frac{m_{\mathrm{T}}}{M_{\mathrm{s}_{1}}}, \\
\gamma & =\frac{\omega_{\mathrm{T}}}{\omega_{n_{1}}}=\frac{1}{1+\mu}, \\
\xi_{\mathrm{T}} & =\frac{c_{\mathrm{T}}}{2 \Phi_{\mathrm{T}} m_{\mathrm{T}}}=\sqrt{\frac{3 \mu}{8(1+\mu)}},
\end{aligned}
$$

where the mass ratio $(\mu)$ is the ratio between the TMD mass $\left(m_{\mathrm{T}}\right)$ and the first modal mass of the structure $\left(M_{\mathrm{s}_{1}}\right)$; the frequency ratio $(\gamma)$ is the ratio between the TMD frequency $\left(\omega_{\mathrm{T}}\right)$ over the first modal frequency of the structure $\left(\omega_{n_{1}}\right) ; \xi_{\mathrm{T}}$ is the damping ratio of the TMD; and $c_{\mathrm{T}}$ is the damping coefficient of the TMD.

The second step is to obtain the optimal gain matrix by solving the ARE in equation (6). As already described above, the ARE can be solved given the weighting matrices $\mathbf{Q}_{\mathbf{z}}$ and $\mathbf{R}_{\mathbf{u}}$. Given the weighting matrices, the ATMD system is thus designed twice for building 1 and building 2 independently. As for the $i$-th ATMD, the matrix $\mathbf{Q}_{\mathbf{z}_{i}}=\mathbf{C}_{\mathbf{y}_{i}}^{T} \mathbf{C}_{\mathbf{y}_{i}}$ is fixed to a constant matrix and the matrix $\mathbf{R}_{\mathbf{u}_{i}}=r_{T}^{i}$ becomes the onevariable design variable to be selected by the designer. By varying the scalar $r_{T}^{i}$, we can obtain the corresponding gain matrix. Using the gain matrix, we can simulate the $i$-th independent ATMD system for the corresponding building and evaluate the control performance in terms of the response reduction ratio. In fact, the scalar $r_{T}^{i}$ has an inverse effect on the control performance of the structure. In other words, as the scalar increases, the control force decreases and the response reduction effect on the structure also decreases. On the other hand, the use of the smaller scalar increases the control force which produces larger reduction effect on the structural response. Therefore, IAS cannot be determined uniquely for the single building, and there exist many optimal solutions to IAS. Since this IAS was used for comparison with the proposed CAS, IAS was determined through the preliminary study to have a similar level of the maximum control forces to CAS. This preliminary parametric study on the scalar $r_{T}^{i}$ leads to the optimal gain matrix comparable to CAS in terms of maximum control force.

3.2. GA-Based CAS Design. The GA is used to optimally design the proposed CAS. For its implementation, the objective function is first defined as the sum of two normalized response ratios of the two buildings where the normalized response ratio corresponds to the ratio of the maximum displacement of the ATMD-controlled structure to the maximum displacement of the original structure without the control system. Thereby, the objective function can be expressed as

$$
J_{\mathrm{obj}}=\sum_{i=1}^{2} \frac{\max _{j=1,2,3}\left\{\max _{t}\left\|\mathbf{x}_{n, \text { controlled }}^{i}\left(t ; \mathbf{d}_{\mathrm{s}}\right)\right\|\right\}_{j}}{\max _{j=1,2,3}\left\{\max _{t}\left\|\mathbf{x}_{n, \text { uncontrolled }}^{i}(t)\right\|\right\}_{j}},
$$

where the superscript $i$ denotes the index of the building, i.e., $i=1$ for left building and $i=2$ for right building; the operator "max" represents the maximum value of the quantity among the subscript indices; the operator $\|\cdot\|$ represents the absolute value of the quantity; and the subscript $j$ denotes the index of the three input excitations. We used three historical earthquakes such as El Centro, Kobe, and Northridge earthquakes; the subscript $t$ means the time period of the earthquake excitations; the subscripts controlled and uncontrolled denote the control and noncontrol systems, respectively; and $\mathbf{x}_{n}^{i}(t)$ represents the $n$-th floor displacement of the $i$-th building. Note that the controlled 
displacement vector $\mathbf{x}_{n \text {,controlled }}^{i}\left(t ; \mathbf{d}_{\mathbf{s}}\right)$ is a function of $\mathbf{d}_{\mathbf{s}}$ which is the design variable of the proposed CAS.

In order to search for the optimal solution to the minimization problem of the objective function in equation (10), we try to search for the optimal location of the ATMD as well as the optimal properties of the ATMD. Hence, the design variables consist of a total of 8 variables such as the installation floor $\left(l_{T}\right)$ for the location of the ATMD, two stiffness values of $\operatorname{ATMD}\left(k_{T}^{1}\right.$ and $\left.k_{T}^{2}\right)$, two damping coefficients of ATMD $\left(c_{T}^{1}\right.$ and $\left.c_{T}^{2}\right)$, and three parameters $\left(r_{T}^{1}, r_{T}^{2}\right.$, and $\left.\alpha_{T}\right)$ for design of active control gain. For comparison purpose, the mass of the coupling ATMD is set equal to the total mass of the two ATMDS of the IAS, i.e., $m_{T}^{c}=m_{T}^{1}+m_{T}^{2}$. The installation floor $\left(l_{T}\right)$ is a discrete number for the floors. The three parameters $\left(r_{T}^{1}, r_{T}^{2}\right.$, and $\left.\alpha_{T}\right)$ are used in the following form:

$$
\mathbf{R}_{\mathbf{u}}=10^{\alpha_{T}} \times\left[\begin{array}{cc}
r_{T}^{1} & 0 \\
0 & r_{T}^{2}
\end{array}\right] .
$$

The GA optimizes the design problem through the iterative evolution process towards better solution. The evolution process begins with a population of $N_{\text {pop }}$ randomly generated individuals denoting the design variables, which are encoded into strings in binary. For the current population of $N_{\text {pop }}$ individuals, each individual is evaluated to compute its fitness based on the objective function. For example, each individual is decoded into ATMD location, ATMD parameters, and weighting parameters for active controller design. By substituting these values into equations (3)-(6) and following the procedure presented in the previous section, we can simulate the seismic responses of the ATMD-coupled adjacent building system with equation (8), followed by the fitness assessment of the corresponding individual. As a result, the better individual with smaller objective function or higher fitness survives by the elitism operation in GA. Next, the roulette wheel selection operation is applied to the current population in order to construct the mating pool with good individuals that are selected based on a probability proportional to its fitness value. The individuals in the mating pool are called parents. Then, the crossover and mutation operations are performed to produce new population of updated individuals with higher fitness. Here, the updated individuals are called offspring or child individuals. The crossover recombines or exchanges the substrings from the parent individuals in the mating pool, and the mutation converts the binary string locally, e.g., binary digit 1 to 0 and vice versa. The cycle of the genetic operations such as elitism, selection, crossover, and mutation is called a generation, and the successive generation yields improvement in the fitness values of the child individuals in the new population. This iterative evolution process continues up to the maximum number of generation or the maximum allowable number of no elite solutions being updated.

\section{Illustrative Example}

As a numerical example to demonstrate the proposed coupling ATMD system, two 10-story shear buildings were considered in this study. Table 1 summarizes the dynamic
TABLE 1: Dynamic properties of two building structures.

\begin{tabular}{lcc}
\hline Properties & Building 1 & Building 2 \\
\hline Floors & 10 & 10 \\
Floor height $(\mathrm{m})$ & 3.80 & 3.80 \\
Floor mass, $m_{j}^{i}$ (tons) & 123.20 & 110.70 \\
Column stiffness, $k_{j}^{i}(\mathrm{MN} / \mathrm{m})$ & 184.55 & 254.55 \\
Damping ratio & Assumed as $1.0 \%$ for $1^{\text {st }}$ and \\
Natural frequency $(\mathrm{Hz})$ & \multicolumn{2}{c}{$2^{\text {nd }}$ modes } \\
$\quad 1^{\text {st }}$ & 0.92 & 1.14 \\
$2^{\text {nd }}$ & 2.74 & 3.40 \\
$3^{\text {rd }}$ & 4.50 & 5.78 \\
\hline
\end{tabular}

properties and frequency characteristics of the two structures. The first 3 natural frequencies of the two buildings tuned out to be distributed closely to each other. Hence, their dynamic behaviors are expected to be very similar to each other. In order to construct the damping matrices, the damping ratio of $1.0 \%$ is assumed for the first and second modes for both buildings. The $1 \%$ assumption results in the two coefficients $\alpha$ and $\beta$ being determined as 0.0866 and $8.6921 \times 10^{-4}$ for building 1 and 0.1073 and $7.0156 \times 10^{-4}$ for building 2 , in the Rayleigh damping model, i.e., $\mathbf{C}_{i}=\alpha \mathbf{M}_{i}+\beta \mathbf{K}_{i}$, respectively.

In the first step of IAS design, the TMD mass was equally chosen to be 15 tons for both buildings, corresponding to TMD mass ratios of $2.3 \%$ and $2.5 \%$, respectively. Thus, the TMD mass of CAS $\left(m_{T}^{c}\right)$ is set to 30 tons. In the second step of active controller design, the parametric studies have been performed separately to determine the optimal values of $r_{T}^{1}$ for building 1 and $r_{T}^{2}$ for building 2 . As already described in Section 3.1, the optimal values of $r_{T}^{1}$ and $r_{T}^{2}$ are determined so that IAS has the similar level of the maximum control forces to CAS. This means that CAS was designed first, followed by IAS. Accordingly, the resultant summary of the IAS design is provided in Table 2.

Now let us consider the CAS design. As aforementioned, the design variables consist of 8 variables. The searching range of the corresponding design variables and the GA parameters used in this study are listed in Table 3. Since the ATMD is not expected to be very effective at the low floors, the design variable of installation floor of the ATMD is only considered for the range between $3^{\text {rd }}$ floor and $10^{\text {th }}$ floor. So, the total number of the floors to be explored is 8 and the bit size of the design variable $l_{T}$ becomes 3 , which matches well on a one-to-one basis, i.e., $2^{3}=8$. In this way, the only discrete variable $l_{T}$ is handled in the proposed GA. The population of one generation is constructed by 50 individuals, whose genes are encoded by a total of 199 bits. We used two-point crossover with a probability of 0.85 and mutation with a probability of 0.2 , and the fitness proportionate selection, also known as roulette wheel selection, is used for recombination. The GA optimization process is terminated as the maximum number of the generation reaches 100,000 or the criterion $N_{\text {same }}$ reaches 3,000 . The final optimization result is illustrated in Figure 2 where the horizontal axis represents the generation number and the vertical axis represents the minimum value of objective function in equation (10). Figure 2 shows the convergence of the average fitness function. The final optimal values of the 
TABLE 2: IAS design results.

\begin{tabular}{|c|c|c|}
\hline Properties & Building 1 & Building 2 \\
\hline $1^{\text {st }}$ modal mass of structure (tons) & 650.43 & 584.44 \\
\hline Mass ratio (\%) & 2.3 & 2.5 \\
\hline Mass, $m_{T}^{i}$ (tons) & 15 & 15 \\
\hline Damping coefficient, $c_{T}^{i}(\mathrm{~N} \cdot \mathrm{s} / \mathrm{m})$ & $1.52 \times 10^{4}$ & $1.98 \times 10^{4}$ \\
\hline Stiffness, $k_{T}^{i}(\mathrm{kN} / \mathrm{m})$ & $4.80 \times 10^{2}$ & $7.32 \times 10^{2}$ \\
\hline \multicolumn{3}{|l|}{ Active actuator } \\
\hline \multicolumn{3}{|l|}{ Weighting matrices } \\
\hline & {$\left[\begin{array}{cc}\mathbf{I}_{10 \times 10} & \mathbf{0}_{10 \times 1} \\
\mathbf{0}_{1 \times 10} & 0\end{array}\right.$} & $\mathbf{0}_{11 \times 11}$ \\
\hline $\mathbf{Q}_{\mathbf{z}_{i}}$ & $\mathbf{0}_{11 \times 11}$ & $\left.\begin{array}{cc}\mathbf{I}_{10 \times 10} & \mathbf{0}_{10 \times 1} \\
\mathbf{0}_{1 \times 10} & 0\end{array}\right]$ \\
\hline & \multicolumn{2}{|c|}{ for both structures } \\
\hline $\mathbf{R}_{\mathbf{u}_{i}}=r_{T}^{i}$ & $5.00 \times 10^{-13}$ & $5.00 \times 10^{-13}$ \\
\hline
\end{tabular}

TABLE 3: GA parameters and searching ranges.

\begin{tabular}{lcc}
\hline Design variables & Searching ranges & $\begin{array}{c}\text { Bit } \\
\text { sizes }\end{array}$ \\
\hline Installation floor & $3 \sim 10$ & 3 \\
$\quad l_{T}$ & & \\
Stiffness & $5,000 \sim 2.56 \times 10^{7} \mathrm{~N} / \mathrm{m}$ & 40 \\
$\quad k_{T}^{1}$ & $5,000 \sim 2.56 \times 10^{7} \mathrm{~N} / \mathrm{m}$ & 40 \\
$k_{T}^{2}$ & & \\
Damping coefficient & $500 \sim 2.33 \times 10^{6} \mathrm{~N} \cdot \mathrm{s} / \mathrm{m}$ & 40 \\
$c_{T}^{1}$ & $500 \sim 2.33 \times 10^{6} \mathrm{~N} \cdot \mathrm{s} / \mathrm{m}$ & 40 \\
$c_{T}^{2}$ & & \\
Parameters of weighting, $\mathbf{R}_{\mathbf{u}}$ & $1 \sim 10$ & 16 \\
$r_{T}^{1}$ & $1 \sim 10$ & 16 \\
$r_{T}^{2}$ & $-16 \sim-1$ & 4 \\
$\alpha_{T}$ & Values \\
\hline GA parameters & 50 & \\
\hline Population & 0.85 & \\
Two-point crossover probability & 0.2 & \\
Mutation probability & & \\
Stopping criteria & 3,000 & \\
$N_{\text {same }}$ & 100,000 & \\
$N_{\text {max }}$ & & \\
\hline
\end{tabular}

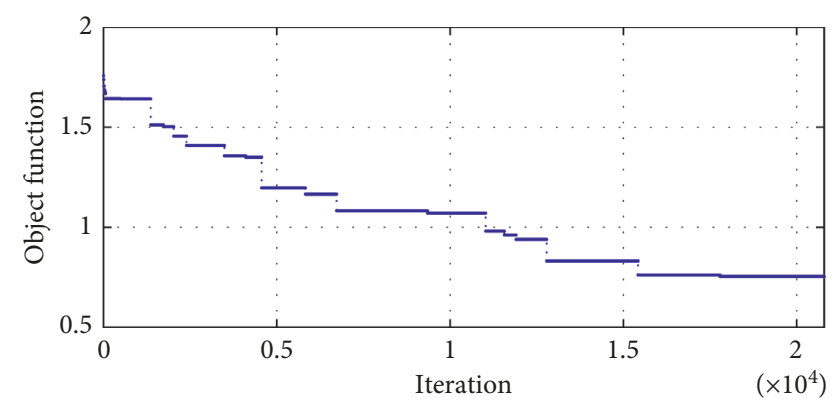

FIgUre 2: Convergence curve of objective function in GA optimization process.

design variables obtained through the iterative optimization process are summarized in Table 4.

When comparing Tables 2 and 4, we can see that the stiffness of passive TMD of CAS was determined to be
TABLE 4: CAS design results.

\begin{tabular}{|c|c|c|}
\hline Properties & \multicolumn{2}{|c|}{ Values } \\
\hline Installation floor & \multicolumn{2}{|c|}{$7^{\text {th }}$} \\
\hline Mass, $m_{T}^{c}$ (tons) & \multicolumn{2}{|r|}{30} \\
\hline \multicolumn{3}{|l|}{ TMD } \\
\hline \multicolumn{3}{|c|}{ Damping coefficient } \\
\hline$c_{T}^{1}(\mathrm{~N} \cdot \mathrm{s} / \mathrm{m})$ & \multicolumn{2}{|c|}{$3.84 \times 10^{3}$} \\
\hline$c_{T}^{\frac{1}{2}}(\mathrm{~N} \cdot \mathrm{s} / \mathrm{m})$ & \multicolumn{2}{|c|}{$3.32 \times 10^{4}$} \\
\hline Stiffness & & \\
\hline$k_{T}^{1}(\mathrm{kN} / \mathrm{m})$ & \multicolumn{2}{|c|}{$2.92 \times 10^{2}$} \\
\hline$k_{T}^{2}(\mathrm{kN} / \mathrm{m})$ & \multicolumn{2}{|c|}{$5.72 \times 10^{2}$} \\
\hline \multicolumn{3}{|l|}{ Active actuator } \\
\hline Weighting mat & & \\
\hline $\mathbf{Q}_{\mathrm{z}}$ & {$\left[\begin{array}{cc}\mathbf{I}_{20 \times 20} & \mathbf{0}_{20 \times} \\
\mathbf{0}_{1 \times 20} & 0 \\
\mathbf{0}_{21 \times 21}\end{array}\right.$} & $\begin{array}{cc}\mathbf{0}_{21 \times 21} \\
\mathbf{I}_{20 \times 20} & \mathbf{0}_{20 \times 1} \\
\mathbf{0}_{1 \times 20} & 0\end{array}$ \\
\hline $\mathbf{R}_{\mathbf{u}}$ & $10^{-13} \times$ & $\left.\begin{array}{cc}7.98 & 0 \\
0 & 3.66\end{array}\right]$ \\
\hline
\end{tabular}

smaller than that of IAS. This difference comes from the characteristics of the interbuilding connection. As already described in Introduction, the interbuilding connection approach is advantageous in that it can achieve the control performance as high as possible while saving the control capacity. In other words, IAS can only exert the passive damping force of TMD on the building where it is installed, and the one-side IAS cannot have any effect on the other building. On the other hand, CAS can exert the passive damping force of TMD interchangeably on both buildings. According to this feature of capacity efficiency, in our proposed optimization process, the stiffness of the passive TMD for CAS was optimized to be smaller than that of TMD for IAS. On the other hand, the two damping coefficients of TMD for CAS also appear to be quite different from those for IAS. However, differently from the stiffness, the sum of the two damping coefficients remains almost the same, e.g., $3.5 \times 10^{4}(\mathrm{~N} \cdot \mathrm{s} / \mathrm{m})$ for IAS and $3.7 \times 10^{4}(\mathrm{~N} \cdot \mathrm{s} / \mathrm{m})$ for CAS. Considering that the damping capacity plays a role in dissipating the vibration energy, it seems that the total damping capacity was maintained at a similar level in the optimization process. Unlike the damping capacity, the stiffness capacity seems to be optimized to have a smaller value in the optimization process since it only needs to transfer the damping forces to both buildings.

4.1. Performance Assessment: Normal Condition. We will now examine the control performances of the two optimal IAS and CAS through the time-history analyses of two adjacent building structures for three historical earthquakes. The earthquake excitations were considered to be one farfield earthquake such as El Centro earthquake (1940) and two near-field earthquakes such as Kobe earthquake (1995) and Northridge earthquake (1994). For comparison purpose, all earthquakes were equally scaled to a PGA (peak ground acceleration) of $0.4 \mathrm{~g}$.

Figure 3 shows the comparative time-history curves of the top-floor displacements between the original 


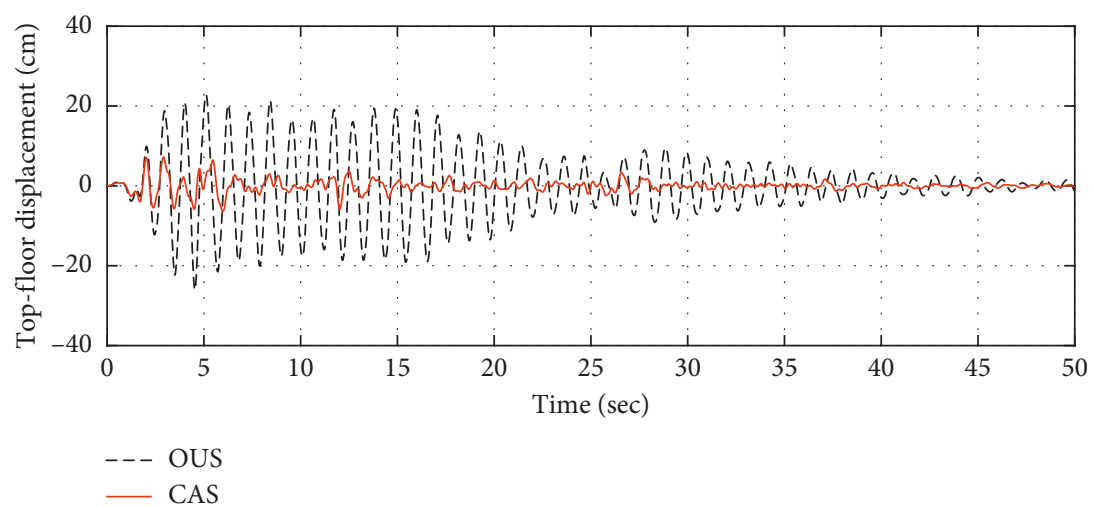

(a)

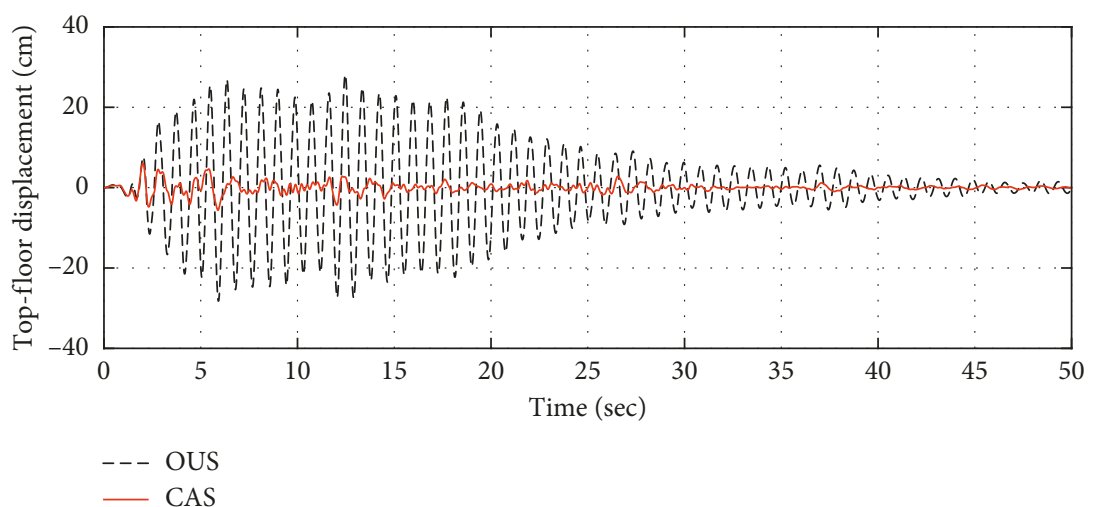

(b)

FIGURE 3: Comparative time-history curves of top-floor displacements between OUS and CAS against El Centro earthquakes. (a) Building 1. (b) Building 2.

uncontrolled structural system (OUS) and the controlled structural system with the proposed CAS when the buildings are subjected to El Centro earthquake excitation. Here, OUS corresponds to the building alone without any control device. The significant reduction effects on the top-floor displacement are clearly observed for both buildings. The maximum top-floor displacements of the OUS are estimated to be $26.05 \mathrm{~cm}$ and $28.25 \mathrm{~cm}$, whereas the maximum displacements of the buildings controlled by the proposed CAS are estimated to be $7.20 \mathrm{~cm}$ and $6.09 \mathrm{~cm}$ for building 1 and building 2, respectively. The response reduction ratios of CAS over OUS reach $72.34 \%$ and $78.45 \%$ for the two buildings. Figure 4 depicts the comparative results between IAS and CAS for the time-history curves of the top-floor displacements of the adjacent buildings subjected to El Centro earthquake. While the proposed CAS shows slightly improved control performance than the IAS, their response reduction ratios are almost the same to each other, e.g., $72.34 \%$ by CAS and $72.09 \%$ by IAS for building 1 and $78.45 \%$ by CAS and $77.15 \%$ by IAS for building 2 , respectively. Figure 5 illustrates the comparative distributions of the maximum displacements along the floors among OUS, IAS, and CAS against the El Centro earthquake. As shown in Figure 5, both IAS and CAS show much improved control performances over OUS, whereas the response reduction ratios of IAS and CAS are similar to each other. As another important measure of seismic performance, we need to take the shear forces and bending moments at the base of the buildings into account. As illustrated in Figures 6 and 7, base shear forces and base overturning moments also show similar tendency between OUS, IAS, and CAS. The IAS shows slightly improved reduction ratio of the maximum base shear force than the CAS, whereas the CAS exhibits greater reduction effect on the maximum base moments than the IAS. In other words, both IAS and CAS show much improved control performance on base shear and base moment over OUS but show very similar performance to each other. More detailed numerical descriptions are given in Table 5.

On the other hand, the control performance of the control system mainly depends upon the control force and power required to operate the actuator. Therefore, the timehistory curves of control force and power for IAS and CAS are additionally compared and shown in Figures 8 and 9. As shown in the figures, IAS uses smaller control capacity than CAS against the El Centro earthquake. Therefore, IAS is a more efficient control system than CAS against El Centro earthquake in that it shows similar control performance to CAS while using smaller control capacity. However, since the earthquakes are highly uncertain, we need to investigate the overall performance and control capacity against the three earthquakes, which are provided in Table 5. 


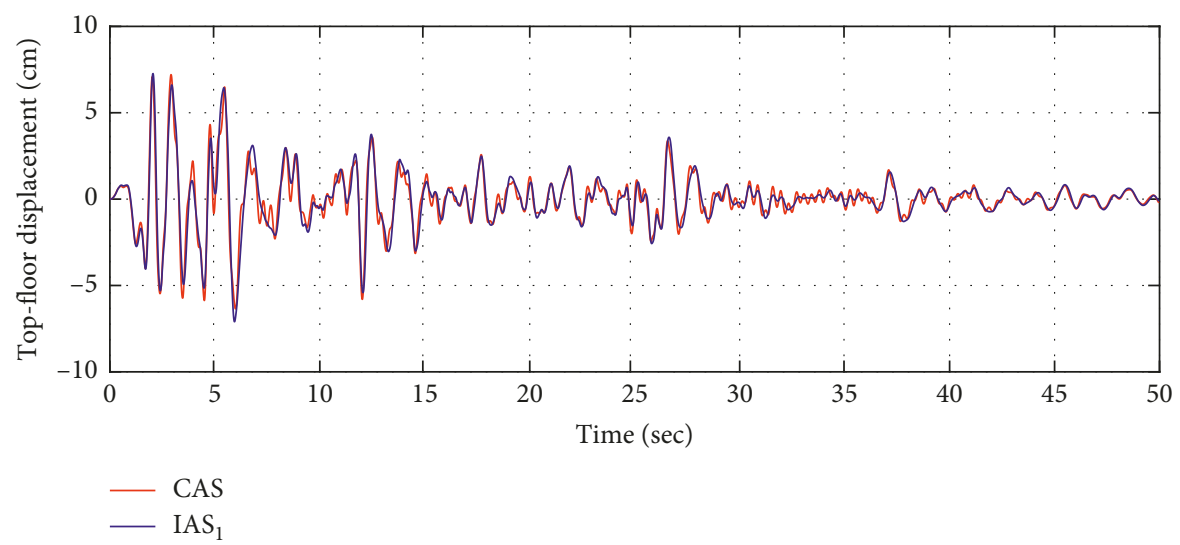

(a)

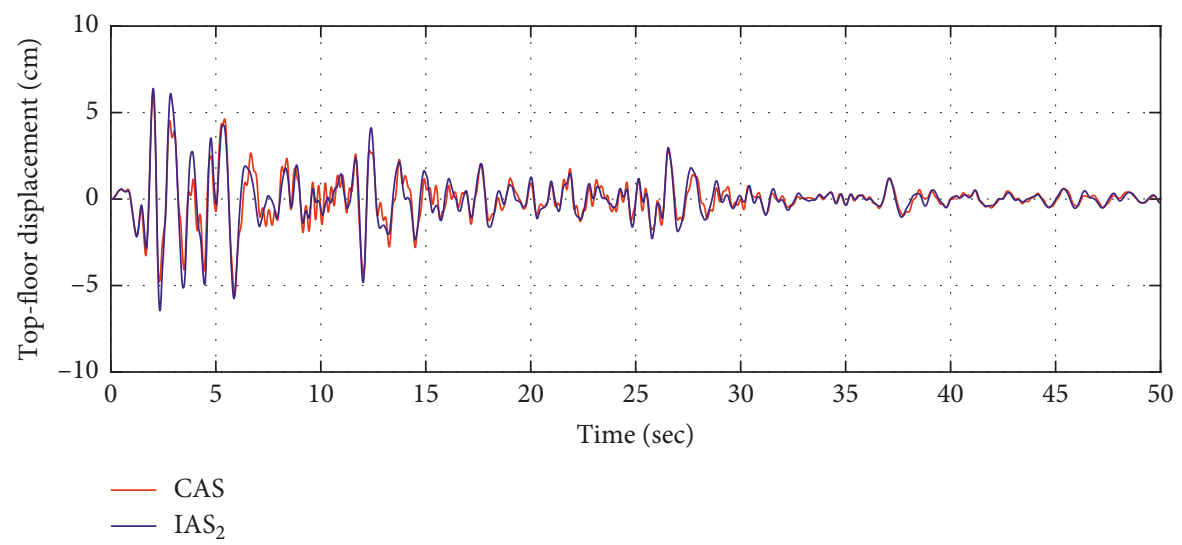

(b)

Figure 4: Comparative time-history curves of top-floor displacements between IAS and CAS against El Centro earthquakes. (a) Building 1. (b) Building 2.

Table 5 summarizes the comparative results of the peak seismic responses and the maximum control requirements among OUS, IAS, and CAS under the cases of the structures being subjected to the three earthquake excitations. The fourth row in each response represents the maximum results against the three earthquake excitations, which correspond to the overall performance against the uncertain earthquake excitations. Note that the minimum values of the results between OUS, IAS, and CAS for each building are denoted in bold, which indicates the best performance for the corresponding building. In other words, since the earthquake is highly uncertain, we can see this maximum result as a measure of the overall control performance of the system for the uncertain seismic events. Focusing on the fourth row in Table 5, the proposed CAS shows better performance on the floor displacement and the base moment than IAS, whereas IAS uses smaller power than CAS. As for other responses and control requirements, both IAS and CAS show a tradeoff relation between building 1 and building 2 . For example, in terms of interstory drift and base shear force, IAS exerts a superior reduction effect on building 1 than CAS, but a poorer reduction effect on building 2 than CAS. In addition, IAS uses smaller control forces against the El Centro and Kobe earthquakes, but larger control forces against the Northridge earthquake than the proposed CAS. Throughout the three earthquakes, the maximum control forces required by IAS are larger than those by CAS for building 1, while CAS requires greater maximum control forces than IAS for building 2. Lastly, IAS produces smaller TMD stroke in building 2, but larger TMD stroke in building 1 than CAS. Therefore, compared with each earthquake, IAS shows higher reduction ratio in more responses than CAS, and the smaller control capacity is used more often. However, in terms of the maximum performance and the maximum control capacity against the three earthquakes, both IAS and CAS have mutually competing overall performance on response reduction while maintaining a similar level of overall control efforts such as control force, power, and TMD stroke.

4.2. Performance Assessment: Event of Actuator Failure. Now, we investigate the seismic performances of both IAS and CAS for the event of actuator failure. We assume the actuator fails only in one of the two buildings. When both actuators fail, IAS and CAS operate in the passive mode, which reduces to the application of passive TMD to neighboring buildings. This topic has already been addressed previously $[2,3]$, so it is not a concern of this study. 


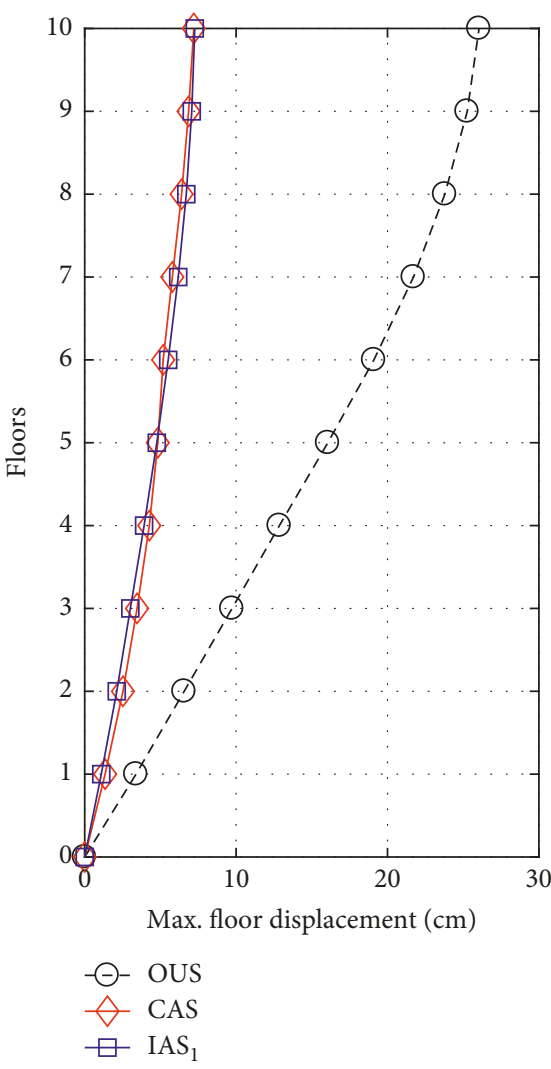

(a)

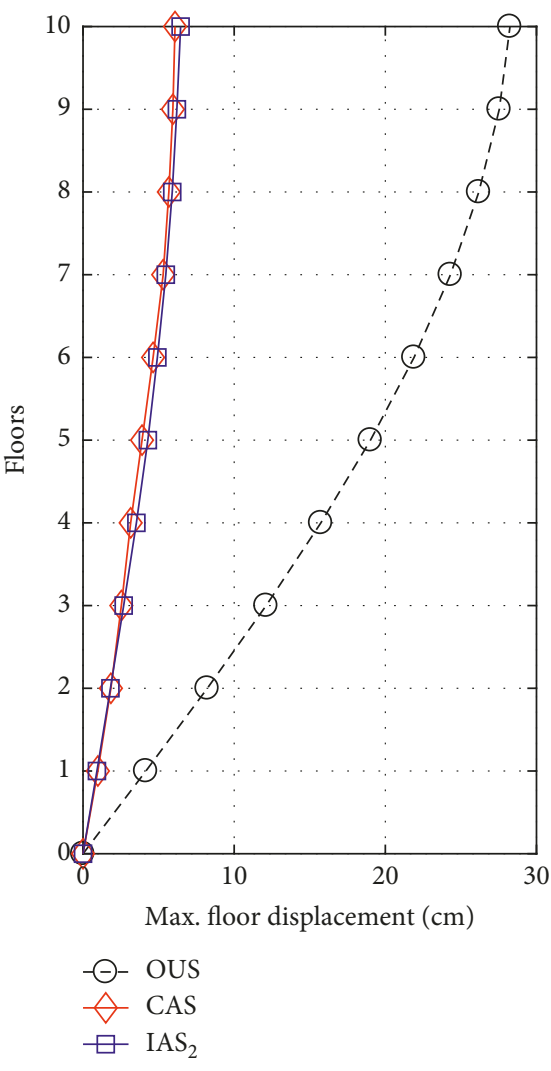

(b)

FIGURE 5: Comparative results of maximum floor displacements among OUS, IAS, and CAS against El Centro earthquakes. (a) Building 1. (b) Building 2.

The maximum seismic responses and the control efforts under the actuator failure are comparatively summarized in Table 6. The results in Table 6 need to be compared with the results in Table 5. First of all, look at the maximum interstory drift results of the IAS. Since the ATMDs in the two buildings work independently of each other, the failure of actuator 1 in the left building does not affect the behavior of building 2 on the right side. Thus, the maximum interstory drift of building 2 shows the same excellent reduction effect as the results of Table 5. However, building 1 experiences significantly increased responses, e.g., from $1.09 \mathrm{~cm}$ to $2.85 \mathrm{~cm}$ for the $\mathrm{El}$ Centro earthquake, from $1.53 \mathrm{~cm}$ to $3.56 \mathrm{~cm}$ for the Kobe earthquake, and from $2.04 \mathrm{~cm}$ to $3.46 \mathrm{~cm}$ for the Northridge earthquake, respectively. However, it still shows slightly improved performance than OUS. These results indicate that ATMD 1 behaves in a passive mode. On the other hand, in CAS, the maximum interstory drifts are increased from $1.35 \mathrm{~cm}$ to $2.38 \mathrm{~cm}$ for the El Centro earthquake, from $1.88 \mathrm{~cm}$ to $2.58 \mathrm{~cm}$ for the Kobe earthquake, and from $2.29 \mathrm{~cm}$ to $3.32 \mathrm{~cm}$ for the Northridge earthquake. Although these responses are somewhat increased compared to their responses in the normally operating conditions, it can be observed that the increase amounts are rather small compared to those of IAS. In other words, in the normal operation, IAS shows better response performance than CAS, whereas CAS performance is better than IAS in the actuator failure. The same applies to the case where actuator 2 fails. In IAS, under the failure of actuator 2, the maximum interstory drifts of building 2 are significantly increased, whereas CAS shows a smaller increase in building 2 response than IAS.

When one of the two actuators fails, IAS only shows passive control performance and there is no room for further improvement of the control performance. However, CAS has the potential to improve the control performance unlike IAS. This is due to the coupling configuration and the corresponding interaction effect. That is, when actuator 1 fails, the left side of the coupling ATMD is still valid in the passive mode and the right side of the coupling ATMD operates in the active mode. Thus, the active control force of the right side is transferred to the left side which, combined with the passive system on the left, still shows hybrid mode behavior.

Overall, compared to CAS, IAS has the largest value in almost all responses for three earthquakes in two buildings, except for the maximum floor displacement and base moment for the Northridge earthquake. On the other hand, the proposed CAS shows higher values than the IAS as a whole in the control effort such as control force and power requirements. This result clearly verifies the adaptive performance of the CAS against the actuator failure. The IAS has a limitation that it cannot adapt to the actuator failure due to the independent control configuration, whereas the proposed CAS can adapt to this emergency by fully utilizing the other normally operating actuator through the coupling configuration. 

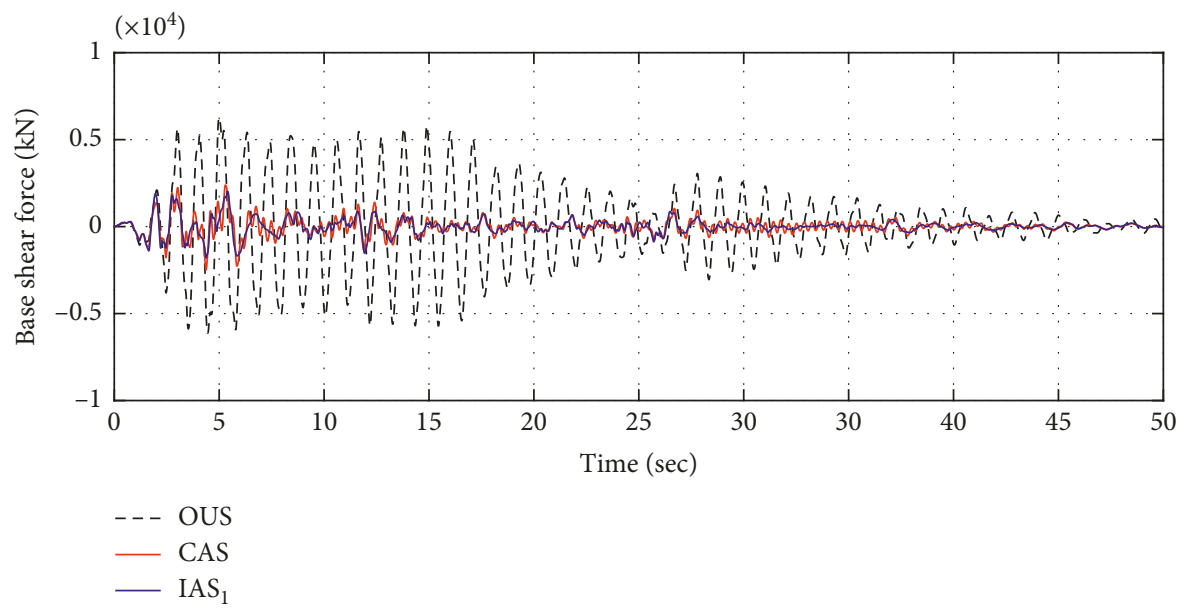

(a)

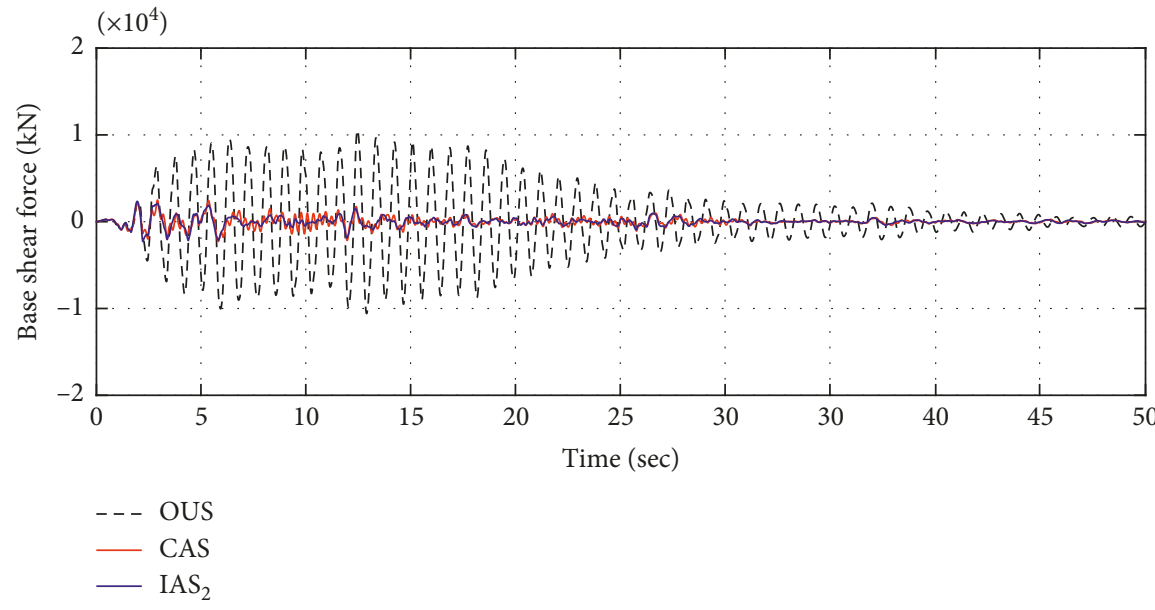

(b)

FIGURE 6: Comparative time-history curves of base shear force among OUS, IAS, and CAS against El Centro earthquakes. (a) Building 1. (b) Building 2 .

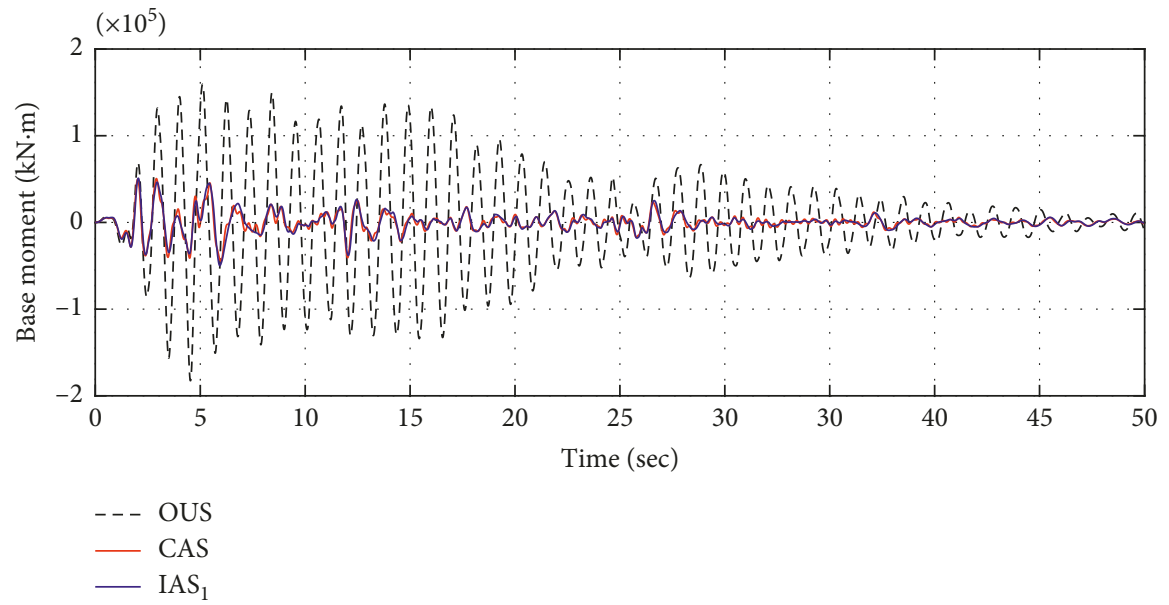

(a)

Figure 7: Continued. 


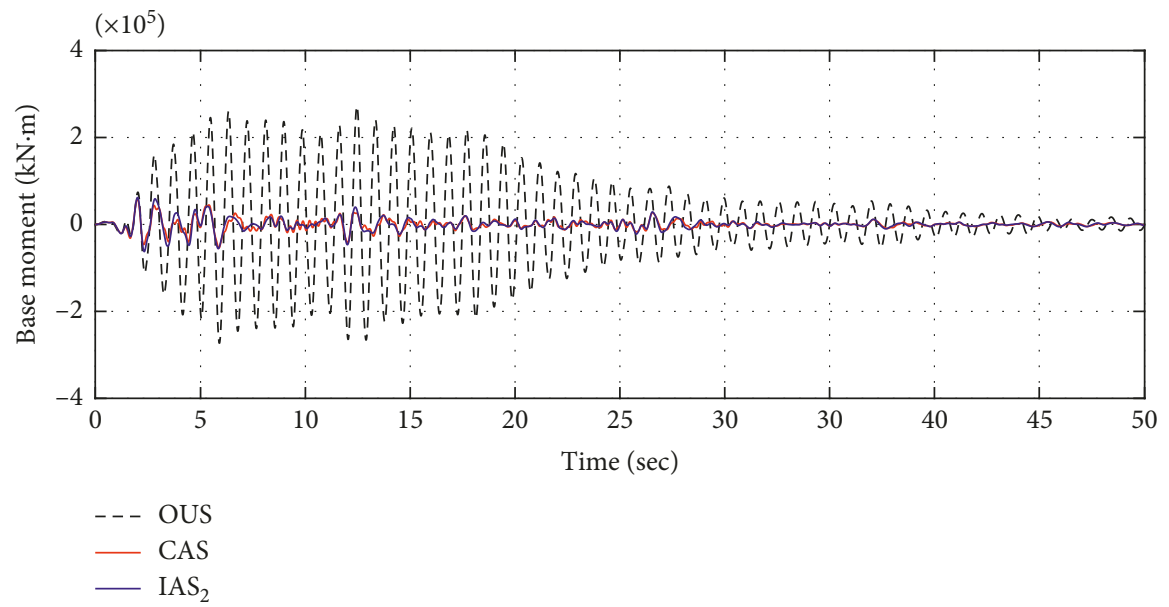

(b)

FIgURE 7: Comparative time-history curves of base overturning moment among OUS, IAS, and CAS against El Centro earthquakes. (a) Building 1. (b) Building 2.

TABLE 5: Comparative results of seismic performances and control requirements among OUS, IAS, and CAS against three earthquake excitations.

\begin{tabular}{|c|c|c|c|c|c|c|c|}
\hline \multirow{2}{*}{ Responses } & \multirow{2}{*}{ EQs } & \multicolumn{2}{|c|}{ OUS } & \multicolumn{2}{|c|}{ IAS } & \multicolumn{2}{|c|}{ CAS } \\
\hline & & Bld. 1 & Bld. 2 & Bld. 1 & Bld. 2 & Bld. 1 & Bld. 2 \\
\hline \multirow{4}{*}{ Maximum interstory drift $(\mathrm{cm})$} & El Centro & 3.39 & 4.16 & 1.09 & 0.96 & 1.35 & 0.98 \\
\hline & Kobe & 3.82 & 4.35 & 1.53 & 1.49 & 1.88 & 1.13 \\
\hline & Northridge & 3.52 & 2.31 & 2.04 & 1.26 & 2.29 & 1.38 \\
\hline & Max. & 3.82 & 4.35 & 2.04 & 1.49 & 2.29 & 1.38 \\
\hline \multirow{4}{*}{ Maximum floor displacement $(\mathrm{cm})$} & El Centro & 26.05 & 28.25 & 7.27 & 6.46 & 7.20 & 6.09 \\
\hline & Kobe & 27.03 & 29.17 & 10.57 & 11.11 & 10.60 & 8.49 \\
\hline & Northridge & 18.48 & 12.78 & 12.31 & 8.26 & 12.28 & 9.46 \\
\hline & Max. & 27.03 & 29.17 & 12.31 & 11.11 & 12.28 & 9.46 \\
\hline \multirow{4}{*}{ Maximum base shear force (MN) } & El Centro & 6.26 & 10.59 & 2.02 & 2.34 & 2.49 & 2.50 \\
\hline & Kobe & 7.05 & 11.08 & 2.82 & 3.80 & 3.48 & 2.87 \\
\hline & Northridge & 6.50 & 5.88 & 3.77 & 3.19 & 4.23 & 3.51 \\
\hline & Max. & 7.05 & 11.08 & 3.77 & 3.80 & 4.23 & 3.51 \\
\hline \multirow{4}{*}{ Maximum base moment $(\mathrm{MN} \cdot \mathrm{m})$} & El Centro & 182.66 & 273.24 & 50.98 & 62.45 & 50.52 & 58.87 \\
\hline & Kobe & 189.56 & 282.18 & 74.16 & 107.50 & 74.32 & 82.15 \\
\hline & Northridge & 129.58 & 123.61 & 86.35 & 79.89 & 86.10 & 91.55 \\
\hline & Max. & 189.56 & 282.18 & 86.35 & 107.50 & 86.10 & 91.55 \\
\hline \multirow{4}{*}{ Maximum control force $(\mathrm{kN})$} & El Centro & - & - & 745.98 & 713.62 & $1,061.93$ & 964.88 \\
\hline & Kobe & - & - & 970.91 & 977.17 & 1317.71 & 1161.65 \\
\hline & Northridge & - & - & 1263.59 & 1419.19 & 929.33 & 1211.96 \\
\hline & Max. & - & - & 1263.59 & 1419.19 & 1317.71 & 1211.96 \\
\hline \multirow{4}{*}{ Maximum TMD stroke $(\mathrm{cm})$} & El Centro & - & - & 208.62 & 160.11 & 222.85 & 224.45 \\
\hline & Kobe & - & - & 254.84 & 254.30 & 282.00 & 283.15 \\
\hline & Northridge & - & - & 373.05 & 215.10 & 375.02 & 377.70 \\
\hline & Max. & - & - & 373.05 & 254.30 & 375.02 & 377.70 \\
\hline \multirow{4}{*}{ Maximum control power (MW) } & El Centro & - & - & 5.54 & 4.98 & 6.60 & 5.88 \\
\hline & Kobe & - & - & 9.04 & 10.32 & 19.55 & 9.24 \\
\hline & Northridge & - & - & 14.59 & 6.31 & 9.93 & 14.37 \\
\hline & Max. & - & - & 14.59 & 10.32 & 19.55 & 14.37 \\
\hline
\end{tabular}

One point to note here is that the maximum TMD stroke in building 1 for the three earthquakes is caused by IAS and in building 2 by CAS. As already mentioned in Introduction, the proposed CAS has much more room for the stroke of the mass block since it is installed between the two buildings. Thus, CAS can handle this large stroke, but it may be a problem to IAS. Since IAS is subjected to the space constraint inside the building, the large stroke can cause further problematic error 


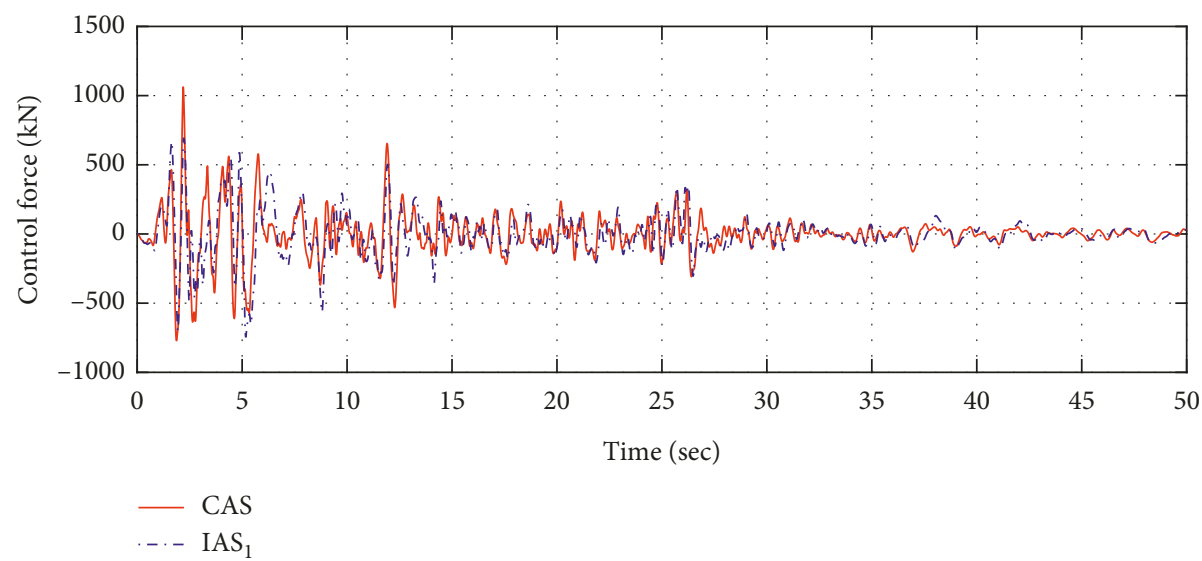

(a)

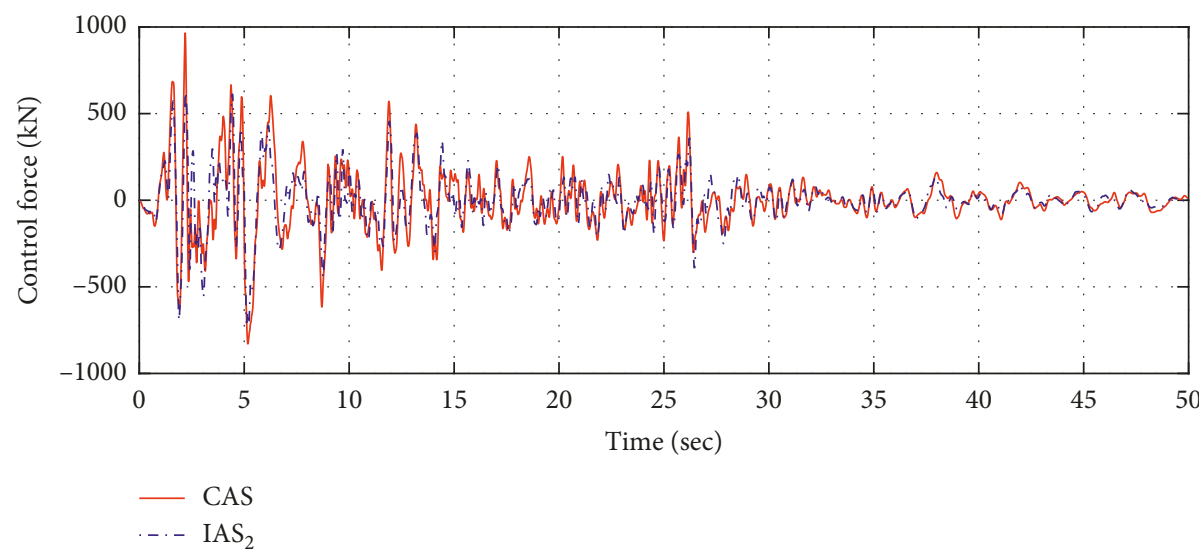

(b)

FIgURE 8: Comparison of control forces exerted by IAS and CAS against El Centro earthquakes. (a) Building 1. (b) Building 2.

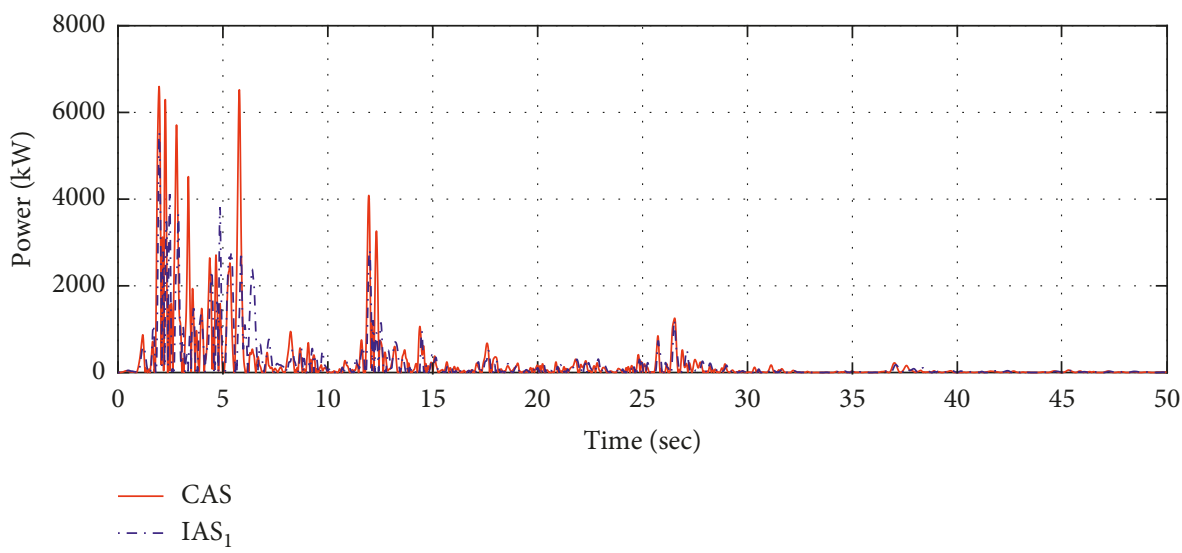

(a)

FIGURE 9: Continued. 


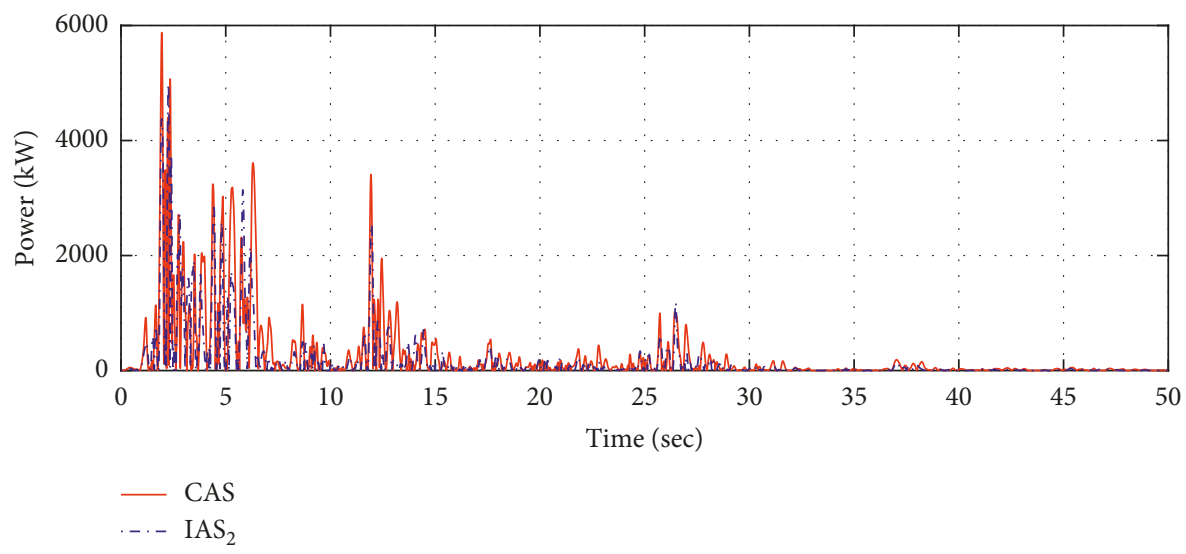

(b)

FIGURE 9: Comparison of control powers required to operate IAS and CAS against El Centro earthquakes. (a) Building 1. (b) Building 2.

TABle 6: Comparison of adaptive performances between IAS and CAS in case of one actuator being failed.

\begin{tabular}{|c|c|c|c|c|c|c|c|c|c|}
\hline \multirow{3}{*}{ Responses } & \multirow{3}{*}{ EQs } & \multicolumn{4}{|c|}{ IAS } & \multicolumn{4}{|c|}{ CAS } \\
\hline & & \multicolumn{2}{|c|}{ Actuator 1 failed } & \multicolumn{2}{|c|}{ Actuator 2 failed } & \multicolumn{2}{|c|}{ Actuator 1 failed } & \multicolumn{2}{|c|}{ Actuator 2 failed } \\
\hline & & Bld. 1 & Bld. 2 & Bld. 1 & Bld. 2 & Bld. 1 & Bld. 2 & Bld. 1 & Bld. 2 \\
\hline \multirow{4}{*}{ Maximum interstory drift $(\mathrm{cm})$} & El Centro & 2.85 & 0.96 & 1.09 & 2.48 & 2.38 & 1.55 & 1.58 & 1.66 \\
\hline & Kobe & 3.56 & 1.49 & 1.53 & 3.47 & 2.58 & 1.49 & 1.98 & 2.20 \\
\hline & Northridge & 3.46 & 1.26 & 2.04 & 2.21 & 3.32 & 1.48 & 2.02 & 1.97 \\
\hline & Max. & 3.56 & 1.49 & 2.04 & 3.47 & 3.32 & 1.55 & 2.02 & 2.20 \\
\hline \multirow{4}{*}{ Maximum floor displ. $(\mathrm{cm})$} & El Centro & 19.77 & 6.46 & 7.27 & 15.62 & 14.39 & 8.42 & 7.38 & 10.84 \\
\hline & Kobe & 25.15 & 11.11 & 10.57 & 24.32 & 19.51 & 10.12 & 11.66 & 15.46 \\
\hline & Northridge & 18.47 & 8.26 & 12.31 & 12.20 & 20.73 & 8.19 & 8.09 & 11.85 \\
\hline & Max. & 25.15 & 11.11 & 12.31 & 24.32 & 20.73 & 10.12 & 11.66 & 15.46 \\
\hline \multirow{4}{*}{ Maximum base shear force (MN) } & El Centro & 5.25 & 2.34 & 2.02 & 6.31 & 4.40 & 3.95 & 2.92 & 4.24 \\
\hline & Kobe & 6.56 & 3.80 & 2.82 & 8.83 & 4.76 & 3.80 & 3.65 & 5.60 \\
\hline & Northridge & 6.39 & 3.19 & 3.77 & 5.63 & 6.13 & 3.76 & 3.72 & 5.01 \\
\hline & Max. & 6.56 & 3.80 & 3.77 & 8.83 & 6.13 & 3.95 & 3.72 & 5.60 \\
\hline \multirow{4}{*}{ Maximum base moment (MN·m) } & El Centro & 138.67 & 62.45 & 50.98 & 151.08 & 100.88 & 81.44 & 51.72 & 104.84 \\
\hline & Kobe & 176.36 & 107.50 & 74.16 & 235.24 & 136.85 & 97.89 & 81.79 & 149.51 \\
\hline & Northridge & 129.50 & 79.89 & 86.35 & 118.02 & 145.40 & 79.23 & 56.72 & 114.58 \\
\hline & Max. & 176.36 & 107.50 & 86.35 & 235.24 & 145.40 & 97.89 & 81.79 & 149.51 \\
\hline \multirow{4}{*}{ Maximum control force $(\mathrm{kN})$} & El Centro & - & 713.62 & 745.98 & - & - & 2050.93 & 1360.33 & - \\
\hline & Kobe & - & 977.17 & 970.91 & - & - & 2051.38 & 1918.71 & - \\
\hline & Northridge & - & 1419.19 & 1263.59 & - & - & 2303.90 & 1288.79 & - \\
\hline & Max. & - & 1419.19 & 1263.59 & - & - & 2303.90 & 1918.71 & - \\
\hline \multirow{4}{*}{ Maximum TMD stroke $(\mathrm{cm})$} & El Centro & 69.92 & 160.11 & 208.62 & 66.92 & 262.05 & 265.28 & 215.32 & 212.58 \\
\hline & Kobe & 77.41 & 254.30 & 254.84 & 71.37 & 305.89 & 301.34 & 314.40 & 311.01 \\
\hline & Northridge & 52.72 & 215.10 & 373.05 & 28.73 & 371.99 & 381.49 & 285.26 & 284.54 \\
\hline & Max. & 77.41 & 254.30 & 373.05 & 71.37 & 371.99 & 381.49 & 314.40 & 311.01 \\
\hline \multirow{4}{*}{ Maximum control power (MW) } & El Centro & - & 4.98 & 5.54 & - & - & 13.15 & 10.01 & - \\
\hline & Kobe & - & 10.32 & 9.04 & - & - & 23.24 & 29.11 & - \\
\hline & Northridge & - & 6.31 & 14.59 & - & - & 26.87 & 9.82 & - \\
\hline & Max. & - & 10.32 & 14.59 & - & - & 26.87 & 29.11 & - \\
\hline
\end{tabular}

in the IAS that does not even work with the passive TMD if the sufficient free space is not taken into account.

\section{Conclusions}

This study deals with the fail-safe control approach of the coupling ATMD system (CAS) against actuator failure in the seismic response control problem of two adjacent structures.
For comparison purpose, the independent ATMD system (IAS) is also taken into account, and both CAS and IAS are described in terms of equations of motion and optimal controller design methods. The seismic performance of the control system has been examined in terms of the actuator failure event of the system. Here, the actuator failure of the system is assumed as an event that the active part of the ATMD is not working but the passive part is still valid. It is 
also assumed that the actuator failure occurs in one of the two actuators. For the comparison purpose, both systems were designed to have similar control performance under the normal operation conditions, and then their adaptive performances have been compared to each other under the emergency condition of one-side actuator failure. The following conclusions can be drawn from their comparative results:

(i) The conventional IAS did not adapt to the emergency condition and only showed passive control performance which corresponded to a significantly degraded level compared to its own normal control performance.

(ii) The proposed CAS showed excellent adaptive performance than the performance-degraded IAS through the interbuilding connection.

(iii) The interbuilding connection of CAS enables the normally operating active control force to be transferred to the other side of the building where the active actuator fails and the TMD only operates in the passive mode. Thus, CAS can still show hybrid mode behavior even in case of actuator failure.

Therefore, the proposed coupling ATMD system can be said to be a fail-safe system that provides more redundancy to the actuator failure event than the independent ATMD system in the seismic response control of two neighboring buildings. In this study, CAS was just designed without considering the actuator failure event. As described above, the main advantage of CAS is that it can still operate in a hybrid mode even under one actuator failure. Therefore, if any new design approach that can consider the actuator failure event in the optimization process can be applied, CAS will have the potential to be more robust against the actuator failure. This issue is worth being addressed as a future study.

\section{Data Availability}

The source code and data used to support the findings of this study have been deposited in the github repository (https:// github.com/syok71/CouplingATMD4twinBldgs).

\section{Conflicts of Interest}

The authors declare that they have no conflicts of interest.

\section{Acknowledgments}

The first author was supported by the research program of Dongguk University, 2018. The corresponding author was supported by the Basic Science Research Program through the National Research Foundation of Korea (NRF) funded by the Ministry of Education (2017R1D1A1B04031418).

\section{References}

[1] J. E. Luco and F. C. P. De Barros, "Optimal damping between two adjacent elastic structures," Earthquake Engineering \& Structural Dynamics, vol. 27, no. 7, pp. 649-659, 1998.
[2] M. M. Abdullah, J. H. Hanif, A. Richardson, and J. Sobanjo, "Use of a shared tuned mass damper (STMD) to reduce vibration and pounding in adjacent structures," Earthquake Engineering \& Structural Dynamics, vol. 30, no. 8, pp. 11851201, 2001.

[3] S.-Y. Ok and S.-M. Kim, "New vibration control approach of adjacent twin structures using connecting tuned mass damper," Journal of the Korean Society of Safety, vol. 32, no. 3, pp. 92-97, 2017.

[4] Y. Q. Ni, J. M. Ko, and Z. G. Ying, "Random seismic response analysis of adjacent buildings coupled with non-linear hysteretic dampers," Journal of Sound and Vibration, vol. 246, no. 3, pp. 403-417, 2001.

[5] H. P. Zhu and Y. L. Xu, "Optimum parameters of Maxwell model-defined dampers used to link adjacent structures," Journal of Sound and Vibration, vol. 279, no. 1-2, pp. 253-274, 2005.

[6] A. V. Bhaskararao and R. S. Jangid, "Harmonic response of adjacent structures connected with a friction damper," Journal of Sound and Vibration, vol. 292, no. 3-5, pp. 710-725, 2006.

[7] R. E. Christenson, B. F. Spencer Jr., E. A. Johnson, and K. Seto, "Coupled building control considering the effects of building/ connector configuration," Journal of Structural Engineering, vol. 132, no. 6, pp. 853-863, 2006.

[8] K.-S. Park and S.-Y. Ok, "Optimal design of actively controlled adjacent structures for balancing the mutually conflicting objectives in design preference aspects," Engineering Structures, vol. 45, pp. 213-222, 2012.

[9] K.-S. Park and S.-Y. Ok, "Modal-space reference-modeltracking fuzzy control of earthquake excited structures," Journal of Sound and Vibration, vol. 334, pp. 136-150, 2015.

[10] S. D. Bharti, S. M. Dumne, and M. K. Shrimali, "Seismic response analysis of adjacent buildings connected with MR dampers," Engineering Structures, vol. 32, no. 8, pp. 21222133, 2010.

[11] M. K. Shrimali, S. D. Bharti, and S. M. Dumne, "Seismic response analysis of coupled building involving MR damper and elastomeric base isolation," Ain Shams Engineering Journal, vol. 6, no. 2, pp. 457-470, 2015.

[12] M. Abdeddaim, A. Ounis, N. Djedoui, and M. K. Shrimali, "Pounding hazard mitigation between adjacent planar buildings using coupling strategy," Journal of Civil Structural Health Monitoring, vol. 6, no. 3, pp. 603-617, 2016.

[13] K.-S. Park and S.-Y. Ok, "Hybrid control approach for seismic coupling of two similar adjacent structures," Journal of Sound and Vibration, vol. 349, pp. 1-17, 2015.

[14] K.-S. Park and S.-Y. Ok, "Optimal design of hybrid control system for new and old neighboring buildings," Journal of Sound and Vibration, vol. 336, pp. 16-31, 2015.

[15] J. C. H. Chang and T. T. Soong, "Structural control using active tuned mass dampers," Journal of the Engineering Mechanics Division, vol. 106, no. 6, pp. 1091-1098, 1980.

[16] D. Hrovat, P. Barak, and M. Rabins, "Semi-active versus passive or active tuned mass dampers for structural control," Journal of Engineering Mechanics, vol. 109, no. 3, pp. 691-705, 1983.

[17] I. Nishimura, T. Kobori, M. Sakamoto, N. Koshika, K. Sasaki, and S. Ohrui, "Active tuned mass damper," Smart Materials and Structures, vol. 1, no. 4, pp. 306-311, 1992.

[18] S. Ankireddi and H. T. Y. Yang, "Simple ATMD control methodology for tall buildings subject to wind loads," Journal of Structural Engineering, vol. 122, no. 1, pp. 83-91, 1996. 
[19] F. L. Lewis, Applied Optimal Control and Estimation, Prentice Hall PTR, Upper Saddle River, NJ, USA, 1992.

[20] D. E. Goldberg, Genetic Algorithms in Search, Optimization, and Machine Learning, Addison-Wesley, Reading, MA, USA, 1989.

[21] S. Sugino, D. Sakai, S. Kundu, and K. Seto, "Vibration control of parallel structures connected with passive devices designed by GA," in Proceedings of the 2nd World Conference on Structural Control, vol. 1, pp. 329-337, John Wiley and Sons Chichester, Kyoto, Japan, 1998.

[22] M. E. Uz and M. N. S. Hadi, "Optimal design of semi active control for adjacent buildings connected by MR damper based on integrated fuzzy logic and multi-objective genetic algorithm," Engineering Structures, vol. 69, pp. 135-148, 2014.

[23] H. Gao, W. Zhan, H. R. Karimi, X. Yang, and S. Yin, "Allocation of actuators and sensors for coupled-adjacentbuilding vibration attenuation," IEEE Transactions on Industrial Electronics, vol. 60, no. 12, pp. 5792-5801, 2013.

[24] G. Bekdas and S. M. Nigdeli, "Mass ratio factor for optimum tuned mass damper strategies," International Journal of Mechanical Sciences, vol. 71, pp. 68-84, 2013.

[25] J. P. Den Hartog, Mechanical Vibrations, McGraw Hill, Inc., New York, NY, USA, 4th edition, 1956.

[26] F. Sadek, B. Mohraz, A. W. Taylor, and R. M. Chung, "A method of estimating the parameters of tuned mass dampers for seismic applications," Earthquake Engineering \& Structural Dynamics, vol. 26, no. 6, pp. 617-635, 1997.

[27] Y. Fujino and M. Abé, "Design formulas for tuned mass dampers based on a perturbation technique," Earthquake Engineering \& Structural Dynamics, vol. 22, no. 10, pp. 833854, 1993. 


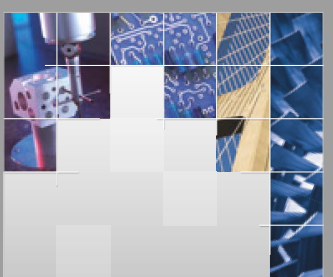

\section{Enfincering}
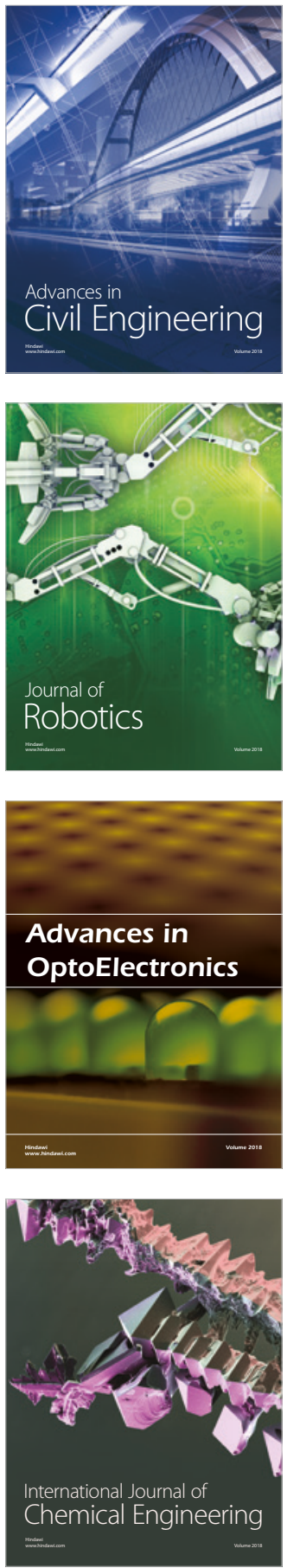

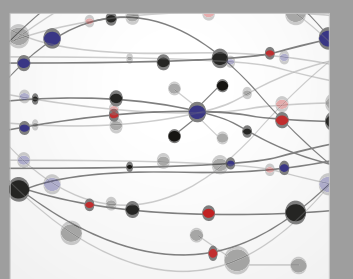

\section{Rotating \\ Machinery}

The Scientific World Journal

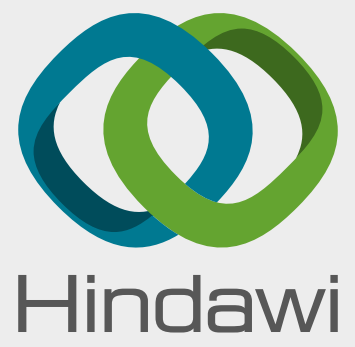

Submit your manuscripts at

www.hindawi.com
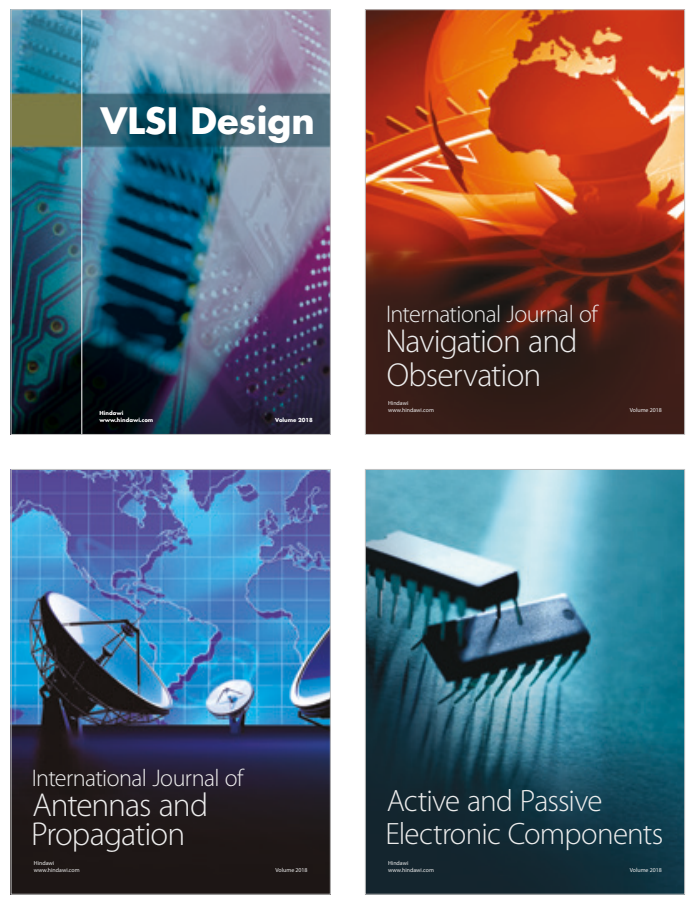
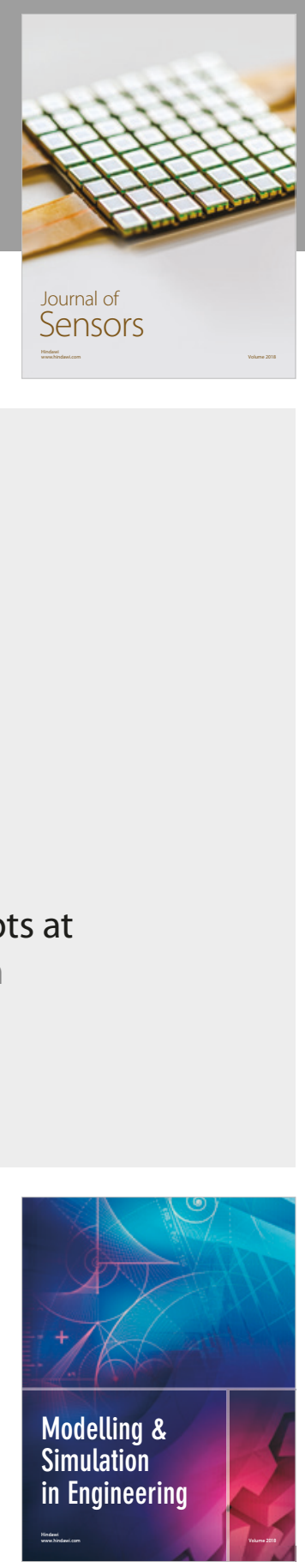

\section{Advances \\ Multimedia}
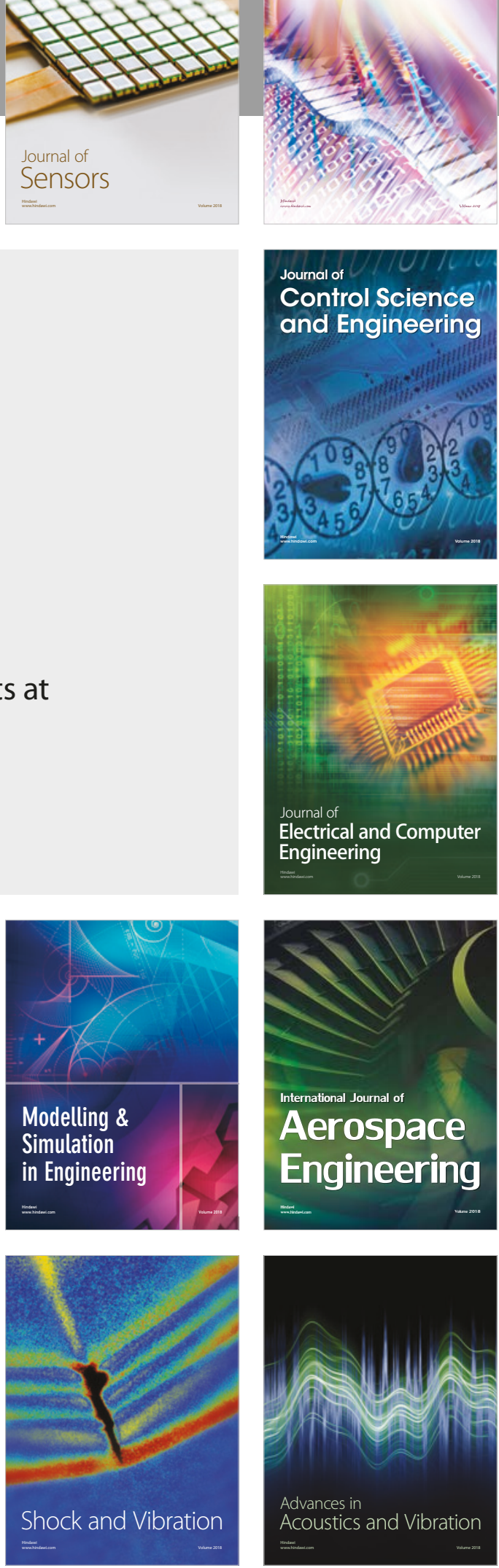